WILLIAM D. NORDHAUS

Yale University

\title{
Oil and Economic Performance in Industrial Countries
}

WITH HINDSIGHT, 1973 marks a turning point of the postwar period, both for the energy market and for overall economic performance. That year ended the great postwar expansion-a period of rapid economic growth, declining unemployment, and a dramatic increase in living standards, all in the context of moderate inflation and economic integration. As measured by real GNP, overall economic growth in the seven largest countries of the Organisation for Economic Co-operation and Development slowed from 5.3 percent annually in $1963-73$ to 2.7 percent in 1973-79, while consumer price inflation rose from 3.6 percent annually to 9.3 percent for the same two periods. ${ }^{1}$ The most significant development from the standpoint of overall economic performance has been the decline in productivity growth from 3.9 percent annually in $1963-73$ to 1.7 percent in $1973-79$.

The year 1973 also marks the first energy crisis-the 1973-74 oil embargo and the first oil price shock. The ensuing pattern of events in energy markets indicates an even sharper discontinuity than in the overall economy. Real producer oil prices increased 2 percent annually over the 1963-

The research for this paper was supported by the National Science Foundation and the Cowles Foundation. I am grateful to members of the Brookings panel for helpful comments, to Steven N. Durlauf and Edward F. Buffie for research assistance, and to Carol J. Clement for skillful typing of the manuscript.

1. The Summit Seven countries are Canada, France, Italy, Japan, West Germany, the United Kingdom, and the United States. 
73 period, then shot up at a 26 percent annual rate from 1973 to mid1980; real oil prices to users in OECD countries fell 1 percent annually for 1963-73, then rose 11 percent annually in 1973-79.

Because 1973 marked a great divide both for the energy market and for overall economic performance of Western economies, it is tempting to hold oil responsible for the lackluster economic performance. Was the timing causal or coincidental? In this paper I review the evidence on the interaction between oil and economic performance in major OECD countries. The key questions addressed below are: What has happened in energy and oil markets over the last two decades? What is the linkage between shortages or price increases in the oil market and economic performance? What are sensible policy responses to the oil shortage?

\section{Historical Perspective on the Energy Market}

The 1955-73 period was one of extremely rapid growth in world oil output and consumption. Table 1 shows the sources and uses of crude oil and natural gas liquids in the free world for the past twenty-five years. The rate of growth of oil demand, at 7 percent a year, was approximately 2 percent faster than the rate of growth of total output, and considerable substitution of oil for other inputs took place in a period of falling prices. Since 1973 there has been a dramatic reversal in production trends, particularly those of OPEC countries. Oil consumption in the OECD countries outside the United States slowed markedly compared to the modest slowdown in the United States and in developing countries.

\section{DEMAND}

Shortly after the first oil crisis analysts were uncertain about the size and timing of the response to the quadrupling of oil prices. With six years of further experience the uncertainties have narrowed considerably. It is now clear that energy demand is closely tied to overall economic activity and, in the short run, highly unresponsive to price. Table 2 presents recent data on U.S. energy consumption for the period before and after 1973. All sectors showed a significant increase in real user prices of energy and a slowdown in the growth of consumption. Overall the weighted average energy price rose an average of 6.8 percent a year during the 
Table 1. Production and Consumption of Crude Oil in the Free World, Selected Years and Periods, 1955-78

\begin{tabular}{|c|c|c|c|c|c|}
\hline \multirow[b]{2}{*}{ Item } & \multicolumn{3}{|c|}{$\begin{array}{l}\text { Amounts (millions of } \\
\text { barrels a day) }\end{array}$} & \multicolumn{2}{|c|}{$\begin{array}{l}\text { Rates of growth (annua } \\
\text { average, in percent) }\end{array}$} \\
\hline & 1955 & 1973 & 1978 & $1955-73$ & $1973-78$ \\
\hline \multicolumn{6}{|l|}{ Production } \\
\hline Total & 13.7 & 45.9 & 47.1 & 6.9 & 0.5 \\
\hline \multicolumn{6}{|l|}{ OECD countries } \\
\hline United States & 6.8 & 9.2 & 8.7 & 1.7 & -1.2 \\
\hline Other $^{a}$ & 0.5 & 2.2 & 3.1 & 8.6 & 7.1 \\
\hline Developing countries ${ }^{b}$ & 0.8 & 3.2 & 4.8 & 8.0 & 8.4 \\
\hline OPEC & 5.6 & 31.3 & 30.5 & 10.0 & -0.5 \\
\hline \multicolumn{6}{|l|}{ Consumption } \\
\hline Total & 14.6 & 48.9 & 50.3 & 6.9 & 0.5 \\
\hline \multicolumn{6}{|l|}{ OECD countries } \\
\hline United States & 8.5 & 17.0 & 18.3 & 3.9 & 1.5 \\
\hline Other ${ }^{\mathrm{c}}$ & 2.7 & 22.2 & 20.9 & 12.4 & -1.2 \\
\hline Developing countries & 3.1 & 7.8 & 8.6 & 5.3 & 2.0 \\
\hline OPEC & 0.3 & 1.9 & 2.5 & 10.8 & 5.6 \\
\hline
\end{tabular}

Sources: U.S. Department of Energy, Energy Information Administration, Annual Report to Congress 1979, vol. 3, DOE/EIA-0173(79)/3 (DOE, 1979), table 2.5 (hereafter EIA Annual Report); American Petroleum Institute, Basic Petroleum Data Book: Petroleum Industry Statistics (API, 1975 and supplementary revisions), table IV.2; Central Intelligence Agency, National Foreign Assessment Center, International Energy Statistical Review, February 27, 1980, p. 2; Oil and Gas Journal, "World Wide Oil Report," vol. 54 (December 26, 1955), pp. 141-263.

a. Canada and Western Europe.

b. Including minor amounts from other industrial countries.

c. Canada, Japan, and Western Europe.

1973-78 period, compared to a slow decline in the years before 1973 . Annual energy demand growth slowed from 4.3 percent before 1973 to 0.9 percent afterward.

The experience since 1973 is useful in calculating an order-of-magnitude estimate of the response of energy demand to the discontinuity in energy prices since 1973, as is shown in the bottom of table 2. The "apparent price elasticities" are calculated as the percentage slowdown in energy demand divided by the percentage acceleration in energy prices, with a correction for growth in income. These calculations are in no way a substitute for more refined multivariate statistical studies, which are discussed below, but they have the virtue of great transparency. According to the estimates, recent behavior is consistent with five-year price elasticities from -0.2 to -0.3 . Assuming this behavior reflects a theoreti- 
Table 2. Energy Demand and Economic Growth in the United States, Selected Periods, 1965-78

\begin{tabular}{lrc}
\hline \multicolumn{1}{c}{ Item } & $1965-73$ & $1973-78$ \\
\hline Growth in real GNP (percent) & 3.7 & 2.3 \\
Growth in real energy prices (percent) & & \\
Residential & -0.1 & 6.1 \\
Transport & -1.5 & 3.9 \\
Industrial & 0.9 & 11.5 \\
Total & -0.1 & 6.8 \\
Growth in energy demand (percent) & & \\
Residential & 3.3 & -0.1 \\
Transport & 5.0 & 2.1 \\
Industrial & 2.9 & -0.9 \\
Total & 4.3 & 0.9 \\
& & \\
Addenda: & & Long run with \\
Apparent price elasticities & Observed & theoretical lag \\
Residential & & \\
Transport & -0.3 & -0.8 \\
Industrial & -0.3 & -0.7 \\
Total & -0.2 & -0.5 \\
\hline
\end{tabular}

Source: GNP-Economic Report of the President, January 1980, p. 204; energy prices and energy demand-EIA Annual Report, tables 4.1, 4.2, 4.4, 4.6, and 4.11.

a. All growth rates are compound annual averages. Real energy prices are user prices divided by the GNP deflator. Energy demand is measured at the end user. Crude price elasticities are calculated as follows. All sectors are assumed to have elasticities with respect to GNP of unity. For each sector, then, the observed price elasticity is equal to the deceleration in growth of demand minus 1.4 divided by the acceleration in real energy price. The calculation of the long-run elasticity with the theoretical lag structure is based on the assumption that all price increase occurred in 1974 and that from 1974 to 1978 relative energy prices were constant. The lag structure in the response of energy demand to price is assumed to be geometric, declining with a ten-year mean lag. This implies that 41 percent of the long-run adjustment took place by 1978 , so the first column is multiplied by 2.44 to obtain the long-run elasticity.

cal lag structure that has an average lag of ten years, the implicit long-run elasticities range from -0.5 to -0.8 . As can be seen from comparison with econometric studies of energy demand presented below, behavior in the United States in the past few years is consistent with both historical and cross-country studies.

Before turning to the formal statistical studies, one might ask whether energy demand has any special features. Energy is desired not for itself but because, in combination with other inputs like capital and labor, it produces useful goods and services like warm houses and cold drinks. The way that energy, capital, and labor are combined to produce desired goods or services is the energy technology of the economy. In reducing 
Table 3. Flexibility in Energy Use for Typical Capital Goods

\begin{tabular}{|c|c|c|c|c|}
\hline \multirow[b]{2}{*}{ Category } & \multirow{2}{*}{$\begin{array}{l}\text { Fraction of } \\
\text { total U.S. } \\
\text { energy con- } \\
\text { sumption in } \\
\text { category } \\
\text { (percent) }\end{array}$} & \multirow{2}{*}{$\begin{array}{l}\text { Lifetime of } \\
\text { capital goods } \\
\quad \text { (years) }\end{array}$} & \multicolumn{2}{|c|}{$\begin{array}{l}\text { Flexibility in energy use } \\
\quad(\text { percent })^{\mathrm{a}}\end{array}$} \\
\hline & & & Short run & Long run \\
\hline $\begin{array}{l}\text { Electrical generation and } \\
\text { large boilers }\end{array}$ & 32 & 25 & $0-3$ & 50 \\
\hline Automobiles and trucks & 18 & 8 & $0-15$ & 70 \\
\hline Space heating & 16 & 20 & $0-10$ & 50 \\
\hline Space cooling & 1 & 10 & $0-10$ & 50 \\
\hline
\end{tabular}

Sources: Energy consumption figures for 1972 from M. Beller, ed., Sourcebook for Energy Assessment (Brookhaven National Laboratory, 1975), p. 13. Lives of capital goods are illustrative data derived from Internal Revenue Service, Bulletin F (1972), lifetimes or data on stocks and new production of capital goods. a. The concept of short-run flexibility is defined as follows: Given the capital goods in existence in 1979, how much reduction in energy input per unit output would be reasonably expected for a doubling of energy prices? This, therefore, does not allow any replacement of the original capital good or change in the amenities (for example, temperature in the house or miles driven). The lower percentage in the column "short-run" corresponds to the instantaneous reaction, while the higher percentage would allow for tuning equipment or insulating. Long-run flexibility allows a complete replacement of capital equipment. Estimates on flexibility are illustrative and were derived from conversations between the author and energy conservation and engineering experts.

energy demand, then, one can either change the technology for producing goods (by substituting capital or labor for energy) or reduce the quantity or shift the mix of final goods and services consumed. Estimated final demand elasticities reflect both. The following discussion focuses on the role of changing technology.

The response of energy demand to output and price depends crucially on the nature of the energy technology. If the technology contains a wide variety of well-established and flexible techniques for producing goods and services, and if the ratios of energy to output of these techniques are highly different, large and rapid changes in the demand for energy can be expected. The opposite appears to be the case, however. There is little flexibility in the set of available technologies. More important, ratios of energy to output are largely determined by the design of the energy-using capital; and the capital is often quite slow to be improved and turned over.

Table 3 presents illustrations of the extent of flexibility in energy use in the long and short run. The four categories of energy-using technology comprise about two-thirds of the energy consumption in the United States. The extent of short-run flexibility in energy use is generally less than onethird of the long-run flexibility. In the case of electricity generation and large boilers, there is for practical purposes no flexibility. 
Table 3 oversimplifies reality in some important ways. For example, if machines have a twenty-year lifetime, in a stationary economy one-half of the inefficient machines will be replaced in ten years. Moreover, if relative prices move sharply enough, some of the older machines may be scrapped or retrofitted before they are twenty years old. On the other hand, there is one way in which table 3 underestimates the length of time needed to react to price changes. In many industries, available capital goods are designed for existing relative prices. When prices change dramatically, capital goods must be redesigned. In the case of the U.S. automobile industry, it will be 1990 before plant and equipment can be completely retooled to make small cars.

A number of thorough surveys have been conducted of the energy demand literature. ${ }^{2}$ Most studies have found income (or output) elasticities at or slightly below 1 . The findings on price elasticities are not in close agreement. Often studies are not careful to separate whether the demand represents a final or wholesale demand, and this ambiguity is reflected in the survey. Table 4 shows a representative set of results from William Hogan's survey-and estimates from my own time-series, cross-sectional study of the Summit Seven countries. Taken literally, it does not appear that much definitive information can be gleaned from these studies because of the wide range of estimates. A good guess would be that long-run final price elasticities are in the -0.7 to -1.1 range, implying that longrun crude price elasticities are from -0.2 to -0.5 .

To summarize the results discussed above, both from an engineering and a statistical point of view energy is indeed a special commodity. It appears to be linked closely to output in the short run, but there is fairly clear flexibility in the ratio of energy to output over the longer run. The exact extent of the flexibility is unclear, although it appears that a doubling of crude energy prices would eventually lead to a reduction of energy demand between 20 and 50 percent. The time span over which this reaction is spread is at least one and perhaps four decades.

2. See particularly Lester D. Taylor, "The Demand for Energy: A Survey of Price and Income Elasticities," in William D. Nordhaus, ed., International Studies of the Demand for Energy (North-Holland, 1977), pp. 3-43; Robert S. Pindyck, "The Characteristics of the Demand for Energy," in John C. Sawhill, ed., Energy Conservation and Public Policy (Prentice-Hall, 1979), pp. 22-45; and William W. Hogan, "Dimensions of Energy Demand," in Hans H. Landsberg, ed., Selected Studies on Energy; Background Papers for Energy: The Next Twenty Years (Ballinger, 1980), pp. 1--92. 
Table 4. Estimates of Long-Run Price Elasticities of Energy Demand for Three Sectors, Summit Seven Countries

\begin{tabular}{|c|c|c|c|c|}
\hline \multirow[b]{2}{*}{ Sector } & \multicolumn{3}{|c|}{ Range of estimated final demand elasticities } & \multirow{2}{*}{$\begin{array}{c}\text { Implicit } \\
\text { elasticity for } \\
\text { primary } \\
\text { energy }\end{array}$} \\
\hline & Hogan & Nordhaus & Best guess & \\
\hline Residential & -0.28 to -1.10 & -0.71 to -1.14 & -0.9 & -0.3 \\
\hline Transport & -0.22 to -1.30 & -0.36 to -1.28 & -0.8 & -0.2 \\
\hline Industrial & -0.49 to -0.90 & -0.30 to -0.52 & -0.7 & -0.4 \\
\hline Aggregate & $\ldots$ & -0.66 to -1.15 & -0.8 & -0.3 \\
\hline
\end{tabular}

Sources: The first column is from William W. Hogan, "Dimensions of Energy Demand," in Hans H. Landsberg, ed., Selected Studies on Energy'; Background Papers for Energy: The Next Twenty Years (Ballinger, 1980), p. 14; the second column, from William D. Nordhaus, "The Demand for Energy: An International Perspective," in William D. Nordhaus, ed., International Studies of the Demand for Energy (North-Holland, 1977), p. 273; the third column is a judgmental weighting of various studies. To obtain an estimate of the crude price elasticity in the fourth column, the final demand price elasticity in the third column is divided by the ratio of retail price to crude price. For transportation, this calculation uses the ratio of the weighted average prices of gasoline for the Summit Seven (Canada, France, Italy, Japan, West Germany, the United Kingdom, and the United States) to the OPEC price (a ratio of 3.8 in 1978). For the other sectors, a weighted ratio is used of final price to crude price for the United States for 1978 (3.0 for residential and commercial and 1.9 for industrial); see EIA Anmal Report, tables 4.1, 4.3, and 4.9.

\section{S U P P LY}

Supply-side developments during the 1970 s were as surprising as those influencing energy demand. Although many significant issues arose, I focus on two that are of central importance to the medium-term behavior of energy markets: the trends in finding energy and the behavior of the OPEC cartel.

Trends in Finding Oil-Recent developments in oil discoveries inside as well as outside the United States have been disappointing. It was hoped that the rise in crude oil prices after 1973 would stimulate considerable drilling and would lead to massive new oil discoveries. In actuality, the first of these expectations was true, while the second was not.

Data on producer oil prices, drilling rates, and reserve additions for the United States are shown in figure 1. The slow decline in real oil prices until 1970, shown by the dashed line, led to a marked fall in the drilling rates shown by the solid line. Beginning in 1971, however, drilling began to increase. The first impetus to drilling was the disappearance of prorationing in oil-producing states in 1971, and this was greatly reinforced by the increase in real oil prices after 1973. By 1978 drilling rates were almost twice their 1971 levels. Clearly the relevant supply-side variable, drilling, is highly responsive to price signals.

By contrast with new drilling activity, new discoveries have been a major disappointment. One measure (not shown) is the finding rate- 
Figure 1. U.S. Crude Oil Price, Drilling Rates, and Additions to Reserves, 1945-78

Drilling rate (millions of feet per year)

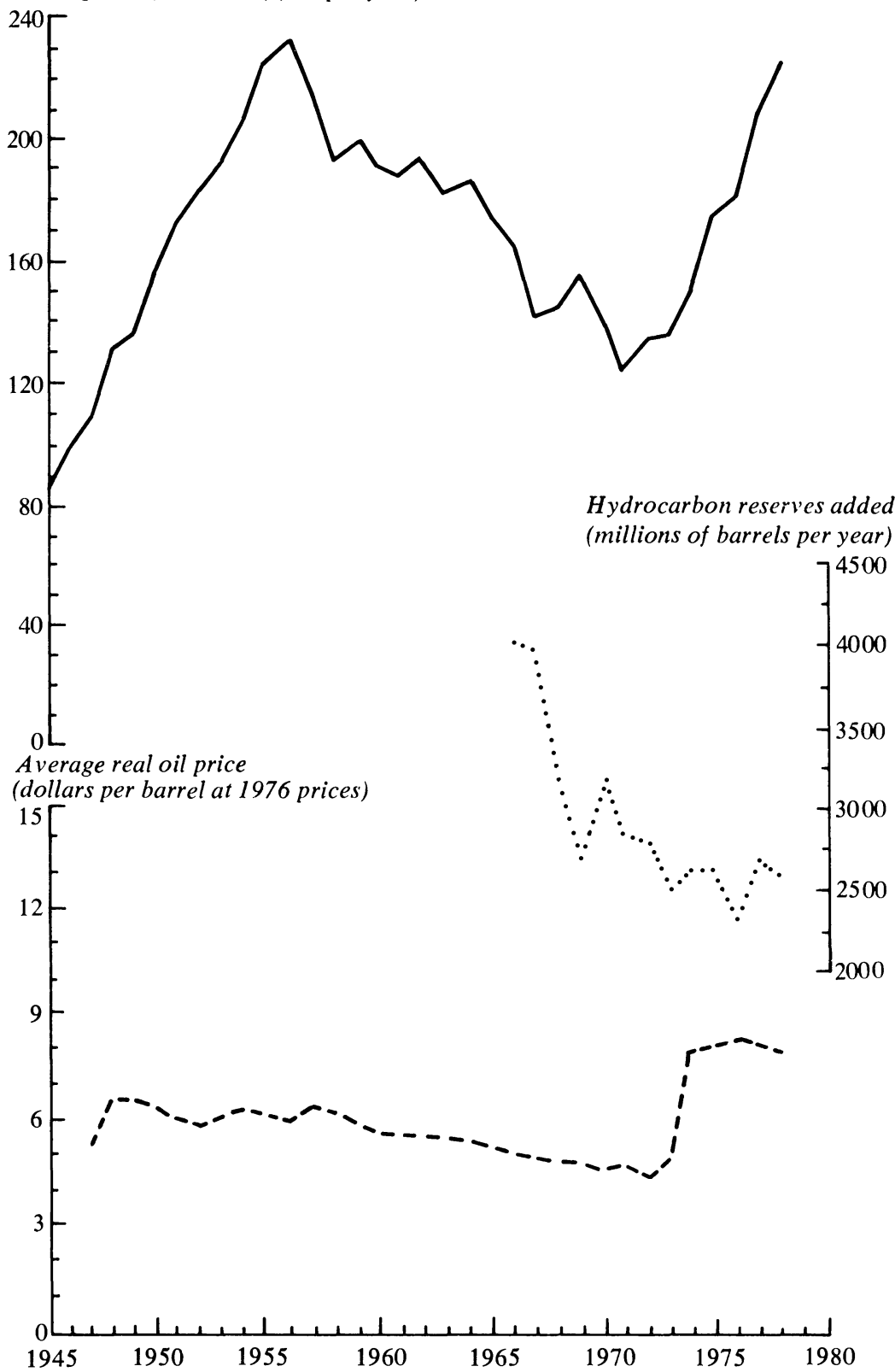

Source: U.S. Department of Energy, Energy Information Administration, Historical Review of Domestic Oil and Gas Exploratory Activity, DOE/EIA-0196 (DOE, October 1979), pp. 3, 7, and 82.

a. Drilling rates are millions of feet a year for all hydrocarbons; hydrocarbon reserves added are millions of barrels a year and exclude revisions and data on Prudhoe Bay, Alaska; real oil prices are based on the wellhead price for crude oil, 1976 prices, dollars per barrel. 
discoveries of ultimately recoverable oil per successful well. Over the postwar period until 1973 the finding rate bounced around a trend that declined about 2 percent annually. After 1973, however, the finding rate took a dive; it fell from approximately 50,000 to about 35,000 barrels a well. The net effect of higher drilling rates and lower finding rates is shown by the dotted line in figure 1 . The striking fact is that the doubling of drilling rates during the 1970s does not appear to have added significantly to the amount of oil and gas found. The amount of hydrocarbons added in 1974-79 (12.9 billion barrels equivalent) is less than in 1969-73 (14.1 billion). Although severe diminishing returns to drilling might not be surprising, there seem to have been negative returns to the increased drilling.

Worldwide trends in proven reserves of crude oil have only recently declined. In the 1974-79 period the apparent discoveries dropped to onehalf the rate of $1969-73 .{ }^{3}$ Recent work by Richard Nehring of the Rand Corporation suggests that the drop in proving reserves in the past few years can be traced to more fundamental trends in finding giant fields. Nehring argues that the problems of estimating trends in discovery could be greatly simplified by focusing only on giant and supergiant fields (those with more than 500 million and 5 billion barrels of recoverable oil, respectively). He estimates that outside the United States, 75 percent of ultimately recoverable oil lies in giant and supergiant fields; in the United States, the figure appears to be closer to 25 percent.

Figure 2 illustrates recent trends in discoveries of giant fields. According to Nehring, the finding rate during the past ten years has fallen to approximately one-third that of earlier periods. Since 1930 each decade has witnessed discoveries of giant fields containing 100 to 200 billion barrels; thus far the 1970s have uncovered only 35 billion barrels. Even more striking is the number of supergiant fields discovered, which fell from five and a half each half decade during 1951-75 to zero during the 1971-75 period. ${ }^{*}$

3. Apparent discoveries are defined as the change in proved reserves plus consumption. Consumption is taken as total production of crude oil plus lease condensates. American Petroleum Institute, Basic Petroleum Data Book: Petroleum Industry Statistics (API, 1975 and supplementary revisions), tables II.1 and IV.1.

4. There appears to be discrepancy between the data on total apparent discoveries and on discoveries of giant fields. Why were proved reserves growing rapidly at the same time that no supergiant fields were discovered? One possible reason is that the increase in proved reserves was basically extending known fields rather than finding new giant fields; the increase in proved reserves may lag discoveries of giant fields. 
Figure 2. Crude Oil Discoveries in Known Giant Oil Fields, Worldwide, through 1975

Billions of barrels per quinquennium

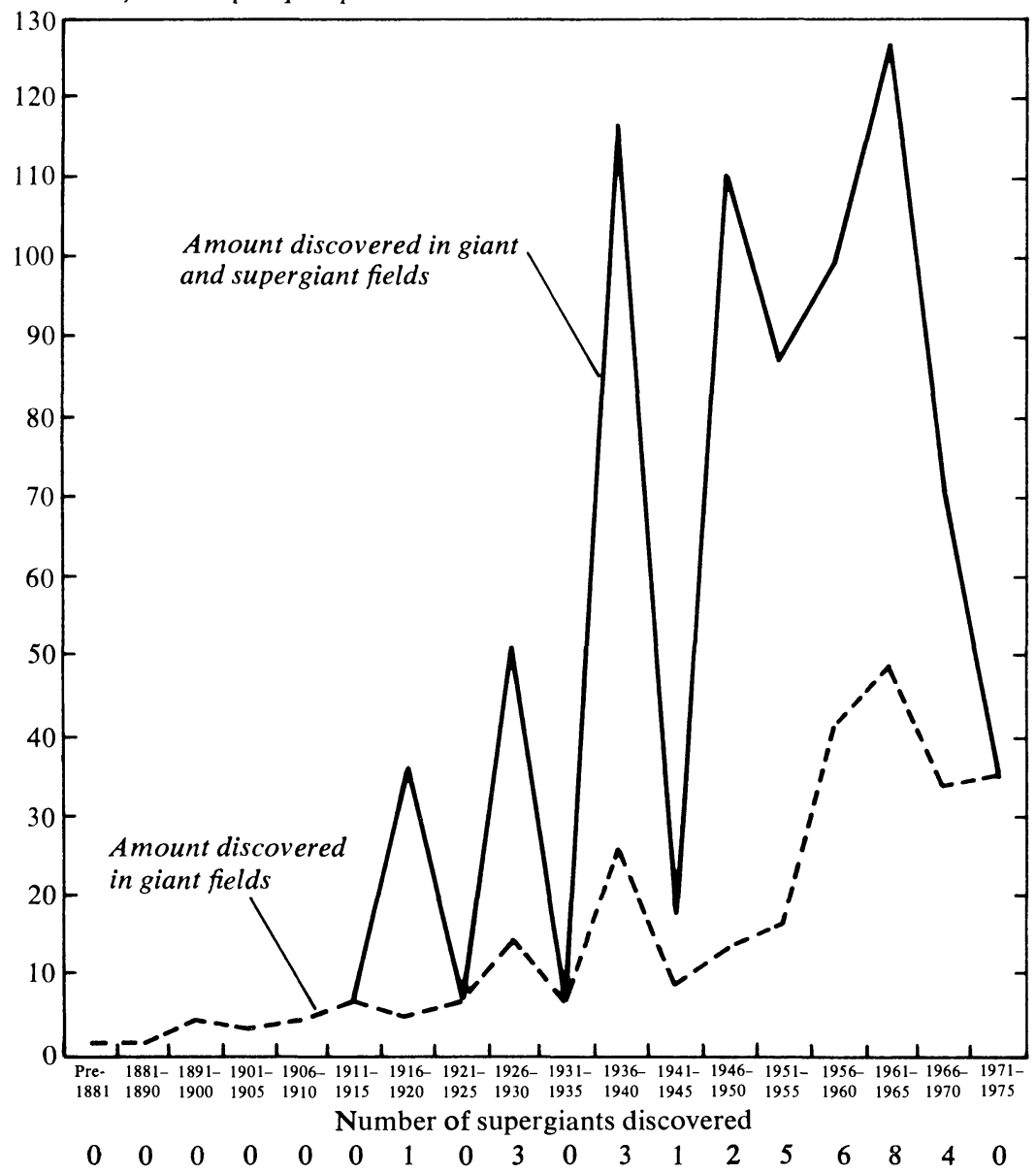

Source: Richard Nehring, Giant Oil Fields and World Oil Resources, R-2284-CIA (Rand Corporation, 1978), p. 43 .

Some of these developments in the past decade are not particularly surprising. The decline in large fields discovered in the United States or supergiants in the world is the plausible outcome of a search process in which the biggest fields are found first. There was no way to know that the decline in discovery of supergiants would come in the 1970s rather than the 1990s. We simply drew a bad hand when Nature dealt the cards. 
There is, in my mind, a significant puzzle in the dramatic plunge in the U.S. finding rate and the inability to add significantly more reserves since 1973 (figure 1). Why should that large plunge in the finding rate coincide with the price rise? I know of no careful discussion of the question, but there are several possible answers. ${ }^{5}$ First, the short-run stock of drilling opportunities might be quite limited. Therefore, as exploratory activity rose rapidly after 1973, drilling encountered increasingly poor prospects where the finding rate was very low.

A second possible explanation might come from perverse incentives in the U.S. federal oil price control structure. If the high-yield prospects were price controlled and the low-yield prospects were not, this might have shifted the mix of drilling toward low-yield prospects and a low finding rate. Since 1976, for example, "stripper" oil wells (wells producing less than ten barrels a day) were decontrolled, while much development drilling was accorded lower-tier prices. In 1978 stripper oil wells yielded $\$ 13.95$ a barrel, while lower-tier wells yielded $\$ 5.46$. Such a regulatory incentive might tilt toward low-yield wells, thereby lowering the overall finding rate.

In addition to these two "genuine" explanations, it could be that recent data are simply unreliable. That data may be revised upward so as to bring the finding rates back to historical trends, although recent revisions have been small. Another possibility is that drillers underreported findings because of the federal price control system; but again, no cases of underreporting have been documented, and there is no direct financial reward to underreporting of reserves.

At this point, no conclusive evidence exists for how much, if any, each of these explanations can contribute to interpreting recent low finding rates. This question is clearly important for understanding what went wrong and for forecasting future trends.

OPEC Supply-The central part of the oil supply picture concerns the role of the OPEC cartel. The history of OPEC is well known and will not be retold here. Rather, I review briefly the conventional views of the effects of OPEC, then develop the view taken in this paper.

The two obvious explanations for the oil price jump in 1973-74 are scarcity and monopoly. The first holds that, because oil as an exhaustible

5. Some clues to the answers are found in U.S. Department of Energy, Energy Information Administration, Energy Programs/Energy Markets, DOE/EIA-0201/16 (DOE, July 1980), chapter 1 . 
resource had been greatly undervalued, the price jump was simply a market correction. Research on the value of oil as an exhaustible resource convinced me that the oil price of the mid-1970s could not be justified by its intrinsic scarcity. ${ }^{6}$

The second view holds that the OPEC price increase was due to the successful monopolization of the oil market. ${ }^{7}$ A number of academic studies during the past few years appear to corroborate the view of OPEC as a monopolist. In The Efficient Use of Energy Resources, I reviewed nine studies of the optimal OPEC monopoly price conducted during the 1975-79 period. Most of the studies of OPEC price behavior indicate that the wealth-maximizing price lies between $\$ 15$ and $\$ 25$ a barrel (in 1979 prices ) for the period between 1980 and the end of the century. ${ }^{8}$ Yet the OPEC price stands today at approximately $\$ 30$ a barrel in 1979 prices. Does this suggest that the OPEC monopoly has overshot or has mistaken views about the correct long-run monopoly price? Or is the current price a temporary disequilibrium that will be restored by a downward drift in the real price in the next few years? Or is the monopoly view of OPEC inaccurate?

Events during the 1977-79 period increasingly cast doubt on the monopoly view of the OPEC cartel. The first development was that countries began to develop their own production targets without much attention to the world oil market. Generally these production targets were low enough to stretch out oil consumption for several decades; they represented the emergence of conservationist tendencies among many countries. ${ }^{9}$ In addition, it appeared that OPEC countries were producing more rather than less than their desired production levels. Saudi Arabia set an interim production target of 8.5 million barrels a day ( $\mathrm{mmbd}$ ) with some

6. See William D. Nordhaus, "The Allocation of Energy Resources," $B P E A$, 3:1973, pp. 529-70, and The Efficient Use of Energy Resources (Yale University Press, 1979).

7. The term monopolist here signifies that OPEC producers behave as a collusive cartel setting output and price so as to maximize their aggregate net worth.

8. Most studies are optimistic about the cost of synthetic fuels, although this may be offset by optimistic assumptions about future growth rates of output. Questions about the appropriate discount rate for the monopolist lead to more uncertainty about the optimal monopoly price than appears in most studies.

9. See U.S. Library of Congress, Congressional Research Service, Mexico's Oil and Gas Policy: An Analysis, prepared for the Senate Committee on Foreign Relations, 95 Cong. 2 sess. (U.S. Government Printing Office, 1979). 
Figure 3. Alternative Views of the Functioning of OPEC

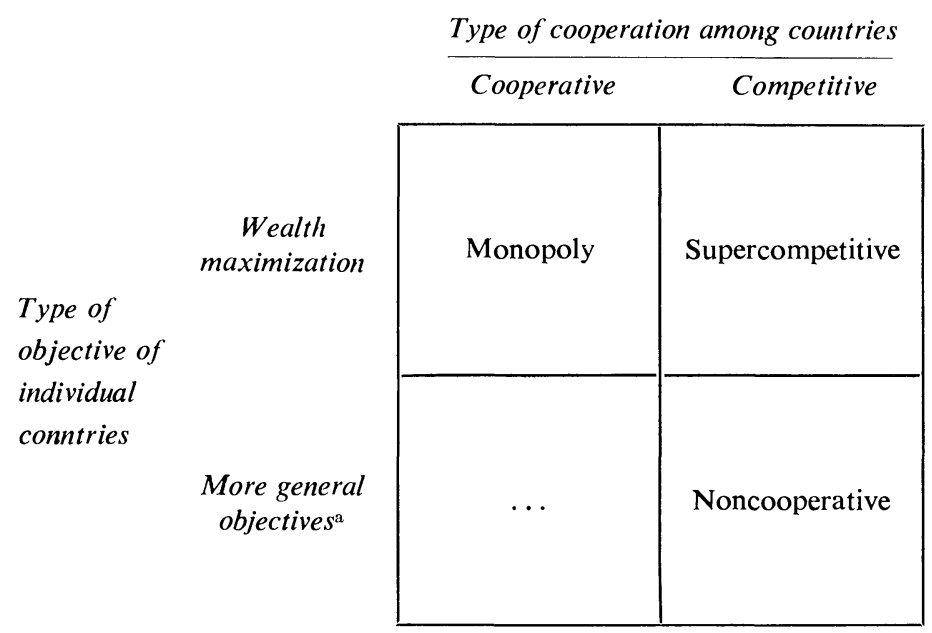

a. More general objectives include survival and protection of economic or social traditions, as well as wealth.

suggestion that the target might be lowered. ${ }^{10}$ Yet it consistently had to produce more (up to $10.5 \mathrm{mmbd}$ ) to stabilize prices. Similar trends were seen for Kuwait and the United Arab Emirates. It is a strange cartel in which countries appear to be producing more than each desires! Finally, OPEC has not always shown the internal cohesiveness of a collusive cartel. Certainly the image of a collusive cartel has been dispelled by the 1980 Iran-Iraq war.

In fact, a new kind of cartel behavior seems to have evolved over the past few years. This behavior can be understood in terms of the characteristics shown in figure 3 above. The first characteristic, shown at the top of the figure, is the nature of the cooperation among the different countries. The monopoly view attributes complete cooperative behavior to the participants, whereas the competitive view assumes noncollusive behavior. ${ }^{11}$ The other characteristic, shown at the left of the figure, reflects

10. See The Future of Saudi Arabian Oil Production, Staff Report to the Subcommittee on International Economic Policy of the Senate Committee on Foreign Relations, 96 Cong. 1 sess. (GPO, 1979); and Central Intelligence Agency, National Foreign Assessment Center, The World Oil Market in the Years Ahead (CIA. August 1979).

11. I use the term supercompetitive to designate that members of the cartel behave noncooperatively and maximize their individual net worth. In perfect capital markets the supercompetitive path is also efficient. 
the objective of individual members of OPEC. Both the monopoly view and the supercompetitive view attribute pure economic behavior to the participants, that is, they are solely interested in maximizing the present value of their oil resources.

A more accurate view-particularly for financially unconstrained OPEC countries like Saudi Arabia, Kuwait, the United Arab Emirates, Iraq, and non-OPEC countries like Mexico and Norway-is that their production targets are determined more by noneconomic considerations (survival of the monarchy in Saudi Arabia, revulsion against Westernization in Iran, values attached to natural resources in Mexico, concerns about the impact of rising exchange rates for manufacturing industries in Norway). This line of reasoning suggests a new view of the OPEC cartel that is more in line with recent developments and behavior. This is the noncooperative view shown in the figure. In a world in which oil prices are (or are expected to be) rising at rates near market returns, countries need not rush to produce oil, especially if they are saturated with revenues. The reluctance to expand production is reinforced if a high level of oil production has undesirable political or social side effects. In recent years countries producing at a high rate have heard the complaint that they are wasting a national heritage and that the revenues are wasted or invested in depreciating currencies or frozen assets.

In such a world how do prices and outputs evolve? A likely outcome is that individual countries set their output targets nonstrategically or noncooperatively - that is, keeping in mind their own resources, expected yields on oil and other assets, economic needs, and political and social constraints, and with little attention to the needs of the cartel. As long as changes in the level of oil prices does not induce a major shift in expectations of future real price increases on oil, the production targets and productive capacity decisions of OPEC members are likely to be relatively insensitive to oil prices.

The noncooperative view of OPEC shares with the supercompetitive view an assumption that production targets of individual countries (and capacity decisions) are set noncooperatively. But, because there are objectives other than wealth for oil production policy, the path of output may well deviate markedly from either a monopolistic or a supercompetitive path. The resultant price path might lie either above or below the supercompetitive or monopoly paths, depending on the preferences of the individual countries. According to this view, OPEC prices today lie above 
the monopoly price because countries, for noneconomic reasons, are slowing down the use of their oil resources. In the next decade or so real oil prices may rise well above the "backstop price," and eventually may fall as the backstop technology is introduced on a large scale. ${ }^{12}$

\section{A Model of Oil and Industrial Economies}

Having reviewed recent developments in the energy market, I now turn to a more careful look at the medium-run interaction between the oil market and overall economic activity. The first section describes a very small aggregate model of the industrial countries called the Medium-term Energy Policy Model (MEPM). In the next section the model is used to make conditional forecasts and estimate the effects of alternative energy and macroeconomic policies.

The MEPM is a compact model of macroeconomic performance and oil markets in industrial (OECD) economies. ${ }^{13}$ The macroeconomic sector of the MEPM is a medium-run model of the functioning of a mixed economy. It allows for both business cycles and for different long-run growth possibilities. In the short run it allows for deviations of output from full employment and for inflation; in the long run it determines growth primarily in terms of supply-side factors. In portraying the oil sector, the model takes a highly stylized view of the functioning of the cartel and of the determination of oil prices; the major difference between this and other models is that here oil prices are endogenously determined.

Before presenting the model in detail, I first describe the nature of the interaction between energy and the economy and the policy issues that will be analyzed.

\section{TIME HORIZON AND POLICY OPTIONS}

It is widely accepted that developments in the energy market have a significant effect on overall economic activity, especially in the short run.

12. Although the backstop price may restrain the OPEC price in the long run, constraints on the introduction of oil shale and other sources will leave holes in the backstop for several decades.

13. The model is fit to data for the OECD or the Summit Seven over the 1960-79 period. For simplicity, I generally refer to the economies as the OECD in the discussion that follows. 
The high degree of short-run association has convinced many that energy and the economy are also tied together in the long run. Part of the confusion about the interaction between energy and economic performance arises because of the analytical approach taken and the time span over which it applies. The two key questions that must be addressed are: Does macroeconomic policy adjust so as to assure that the policy targets are attained? Does the capital stock adjust to the new relative price configuration?

There are three different time spans over which it might be desirable to measure the interaction between energy and the economy. The short run, the period before fiscal and monetary policy markedly affect economic outcomes, is one possibility. Given delays in recognition, decision, and impact, the short run is one or two years. This paper does not address the issue of short-run impacts because this period is less central to design of sensible energy policies.

The paper focuses, instead, on the medium and long run. After a few years, in the medium run, economic policy can move the economy reasonably close to the desired level of utilization of resources. But there are serious constraints to adjustment to an oil shock because the capital stock is given. Over a period of about two to twenty years, then, the constraints of the historically given capital stock are the major determinants of the interaction between energy and the economy.

In the long run, the interaction is determined by the fundamental forces of technology and tastes. That is, a reduction in energy demand can be met with relatively low cost if one of two conditions is satisfied: if other inputs are easily substitutable technically for energy or if other final goods are satisfactory substitutes for energy-intensive goods. Thus, if insulated homes use much less energy, the first condition is met; the second is met if going to the beach is an acceptable alternative to being in an air-conditioned house.

Given the structure of the interaction between energy and the economy, what is the role of policy in managing the U.S. energy problem? In general, responses can be divided into three general categories, as follows, depending on how policymakers combine overall macroeconomic policy and energy sector policies.

Business-as-usual policies assume energy problems do not require special treatment. Macroeconomic policy responds in the traditional way 
to unemployment, inflation, and the balance of payments; energy policy continues to follow the traditional regulatory or free-market approaches. In this first option, then, either energy is not a special kind of economic problem, or one might be skeptical about the efficacy of policies aimed specifically at energy.

Slow-growth policies might be called for as a means of reducing energy consumption and oil imports. Such a path might be advisable if the cost of oil imports were extremely high (say, causing a balance-of-payments crisis) and no other instruments were available for curbing oil use, or if a country was so large that excessive oil demand spilled over into world markets and raised world prices.

Energy-sector policies, a third option, would be to set macroeconomic policy by the usual principles (responding to inflation, unemployment, and the balance of payments), but to use highly focused energy-sector policies to curb energy consumption or oil imports. The basic rationale for this division of labor is that over the long run there is considerable latitude for changing the energy intensiveness of the economy-through changing the relative price of energy to nonenergy goods, perhaps buttressing price changes by nonprice policies. ${ }^{14}$

"Energy policy" covers an enormous variety of actual instruments. Examples that have been used in the United States include policies that have affected energy prices (import tariffs, gasoline taxes, price controls, and public utility regulation of price and entry) and nonprice policies (general technical standards for capital equipment, specific regulations for plants, and environmental regulations ).$^{15}$

In the present macroeconomic model it is impossible to use a level of detail that allows viewing the fine grain of energy policy. ${ }^{16}$ Rather, I pro-

14. The evidence on the long-run trade-off supports the view of considerable flexibility. See National Research Council, Report of the Modeling Resource Group of the Committee on Nuclear and Alternative Energy Systems, Energy Modeling for an Uncertain Future (National Academy of Sciences, 1978), chapter 3.

15. For a thorough list and review of energy policies in the United States, see Energy Information Administration, Energy Programs/Energy Markets.

16. The only study of the overall effects of U.S. energy policy is contained in Energy Information Administration, Energy Programs/Energy Markets. See tables 3.5 and 3.6, in which it is shown that the total effect of energy programs by 1990 will be to reduce energy consumption by 2 percent and to increase oil imports by 0.1 mmbd. In price-equivalent terms, the latter amounts to a subsidy to oil consumption of one cent a gallon. 
ceed as if policies are convertible into a "price-equivalent" energy policy. ${ }^{17}$ This simplifies the modeling and its interpretation. The one distinction made in the analysis - which is of considerable importance in design of policy - is the issue of whether the price-equivalent policies actually enter into price indexes and therefore raise the rate of inflation. As will be noted below, there is some premium in an inflation-constrained world to design energy policies that raise the "shadow price" of energy without raising the market price.

The following sections present the details of the model. The three important components of the MEPM are the macroeconomic model, particularly the production function; the energy sector, which links OPEC oil supply with OECD oil demand; and the objectives of economic policy. The equations that are presented were estimated for the Summit Seven countries over the 1960-79 period.

\section{MACROECONOMIC RELATIONS}

The first component, the macroeconomic model, is best described as a standard neo-Keynesian model with inertial inflation. Inflation is inertial in the sense that it tends to persist at the same rate unless shocked. Potential output is given in the short run, and macroeconomic policy can determine actual output and employment. In the long run the level of potential output can be influenced by energy and macroeconomic policy. The form of the aggregate production function underlying the analysis is one of the model's unusual features.

I argued above that the nature of technology defining energy use was the key to understanding economic performance and dilemmas confronting policymakers-energy use is closely tied to the capital stock, and patterns of consumption and productivity change mainly as the capital stock changes. The present model reflects these characteristics by assuming a vintage production function in which the energy-output ratio is fixed for a given vintage of capital over its lifetime, and more efficient use of energy

17. Thus if a fuel economy standard is binding and has a penalty of $\$ 100$ a mile per gallon for each automobile, this would be treated at the equivalent of a $\$ 1.25$ gasoline tax. This example assumes an automobile whose lifetime is 50,000 miles that gets 25 miles a gallon, with no discounting and constant prices. If a company exceeds the standard, the "shadow tax" would be zero. 
can only be introduced through new capital goods. Thus potential output and the relative use of energy, capital, and labor will be determined by past investment decisions. Changes in relative prices affect the technology of new capital goods, and through them, the levels of potential output and the mix of inputs. ${ }^{18}$

A more complete description of the production structure is as follows. Labor and oil are combined in a two-factor constant elasticity-of-substitution production function. Labor inputs can be considered as a proxy for a more general "neoclassical" factor of labor and investment. For each vintage of capital, the combination of labor and oil is chosen to minimize discounted expected costs of producing output over the life cycle of the capital. But once the vintage is in place, the pattern of oil use is assumed to be given. Aggregate output is then simply the sum of the output of different vintages; similarly, inputs of labor and oil are the sum of the (fixed coefficients) input requirements needed to produce the output in different vintages. ${ }^{19}$

It is unfortunate that the model does not include a full treatment of investment, thereby allowing for more realistic short-run dynamics and for a fuller feedback from energy prices to investment and productivity. Capital was not included because of difficulties in collecting data on OECD capital stocks and because this would require the introduction of asset markets. I doubt that such a complication would greatly change the outcomes; it is the price of oil relative to the price of the neoclassical factor, and not the interaction between labor and capital, that will dominate medium-run and long-run economic performance.

More concretely, potential output using vintage $\theta$ capital in year $t$ is given by

$$
Q_{t, \theta}^{*}=\left[(1-\gamma)\left(A_{t} E_{t, \theta}^{*}\right)^{-\rho}+\gamma\left(B_{t} O i l_{t, \theta}^{*}\right)^{-\rho}\right]_{-\frac{1}{\rho}},
$$

18. I define potential output as that level of GNP that would be produced if the unemployment rate were equal to the nonaccelerating-inflation rate of unemployment (NAIRU), or the natural rate for short.

19. Three assumptions are made in constructing the production function. First, vintages are assumed to crumble at a fixed exponential rate equal to 10 percent annually, but no actual scrapping occurs. Second, technological change is either labor or energy augmenting, but always disembodied. Finally, the productivity slowdown that occurred in 1973 is assumed to affect only the labor-augmenting technological change. This accounts for the fact that the same time terms appear in both the energy and production equations below. 
where

$Q_{t, \theta}=$ output produced by vintage $\theta$ in year $t$ (with $Q_{t, \theta}^{*}$ the corresponding potential output)

$E_{t, \theta}=$ employment used on vintage $\theta$ in year $t$ (with $E_{t, \theta}^{*}$ the corresponding potential employment)

$O i l_{t, \theta}=$ oil used on vintage $\theta$ in year $t$ (with $O i l_{t, \theta}^{*}$ the corresponding potential oil used)

$A_{t}, B_{t}=$ levels of disembodied factor-augmenting technological change

$\gamma=$ distribution parameter

$\rho=$ a substitution parameter such that $\sigma=1 /(1+\rho)$ is the elasticity of substitution between the neoclassical factor and oil.

If relative price and technology expectations are static, and if higherorder terms are neglected, the cost-minimizing input proportions are given by

$$
Q_{t, \theta}^{*}=c_{1} A_{t}\left(\frac{W_{\theta}}{\text { Cpoil }_{\theta}}\right)^{\sigma \gamma} E_{t, \theta}^{*},
$$

where Cpoil $_{\theta}$ is the retail or user price of oil and $W_{\theta}$ is wage rate, each measured at the time the decision is made for vintage $\theta$, and $c$ is an inessential constant.

Assuming that labor grows smoothly at rate $g$ and that vintages are built to accommodate new labor plus that freed from depreciated vintages, total potential output, $Q_{\imath}^{*}$, is given by

$$
\frac{Q_{t}^{*}}{E_{t}^{*}}=c_{1} A_{t} \sum_{v=0}^{\infty}\left(\frac{W_{t-v}}{C p o i l_{t-v}}\right)^{\sigma \gamma}\left(1+c_{3}\right)^{-v}
$$

where $\left(1+c_{3}\right)=(1+\delta)(1+g)$, and $\delta$ is the depreciation rate for each vintage.

External information rather than sample data is used to estimate the key parameters of the production function. The retail share of oil in the early 1970s was 4 percent in national accounts data, so $\gamma$ is constrained to 0.04 . The $\sigma$ is set at 0.8 (see a discussion of the reasons for this value below). Estimating the remaining terms from sample data, I find that the rate of labor-augmenting progress in the OECD countries was 4.0 percent a year up to 1973, and that the rate of energy-augmenting progress appears to have been slightly slower, about 3.2 percent a year. Trend terms for the period since 1973 indicate a slowdown in the growth in potential 
labor productivity to only 2.5 percent a year during the 1973-79 period. The final equation, after some manipulation, is ${ }^{20}$

$$
\begin{gathered}
\log \left(\frac{Q_{t}^{*}}{E_{t}^{*}}-0.9 \frac{Q_{t-1}^{*}}{E_{t-1}^{*}}\right)=-\begin{array}{c}
-3.1+0.0395 \text { time } \\
(0.12)(0.0062)
\end{array} \\
-0.03 \log \left(\frac{\text { Cpoil } l_{t}}{W_{t}}\right)-0.008 t 73-0.149 \text { dum } 73, \\
(0.022) \quad(0.106)
\end{gathered}
$$

where $t 73$ is a variable that equals zero until 1973 and grows 1 a year thereafter; $d u m 73$ is a variable equal to 1 in 1973 and to zero otherwise; and 0.9 is approximately equal to $1+a-g-\delta, a=\dot{A} / A$.

By similar manipulation, an equation can be derived for the demand for energy. Again it is assumed that, on any existing vintage of capital, and aside from trends in disembodied technological change, oil and labor are used in fixed proportions. This implies

$$
\operatorname{Oil}_{t, \theta}=c_{4} \frac{A_{t}}{B_{t}}\left(\frac{W_{\theta}}{\text { Cpoil }_{\theta}}\right)^{\sigma} E_{t, \theta} .
$$

By adding vintages, a final equation is derived:

$$
\begin{gathered}
\log \left(\frac{\text { Oil }_{t}}{E_{t}}-0.9 \frac{\text { Oil }_{t-1}}{E_{t-1}}\right)=\begin{array}{c}
5.0+0.0080 \text { time } \\
(0.24)(0.010)
\end{array} \\
\quad-0.008 t 73-0.149 \text { dum } 73-0.8 \log \left(\frac{\text { Cpoil }}{W_{t}}\right), \\
\bar{R}^{2}=0.46 ; \text { Durbin-Watson }=1.7 ; \text { standard error }=0.17 .
\end{gathered}
$$

The coefficient 0.9 in equation 2 assumes that $b=\dot{B} / B$ is close to zero and that the slowdown in productivity since 1973 is a consequence of a reduction in the growth of labor-augmenting technological change.

A key parameter of the model is the elasticity of substitution between oil and labor, $\sigma$. This parameter was set at 0.8 after an examination of energy-demand studies reviewed in the first part of the paper and after a brief excursion to examine in-sample substitution behavior.

Table 4 indicates that a best-guess estimate of the final price-elasticity

20. Here and elsewhere in the paper the numbers in parentheses are standard errors of coefficients. Where no standard error is reported, the coefficient is determined a priori. 
of demand for energy products is -0.8 . As shown above, the price elasticity (with sign changed) is a first-order approximation of the elasticity of substitution. Therefore a figure of 0.8 is a good guess for the value of $\sigma$. One shortcoming of this approach is that the demand studies reviewed generally refer to demand for energy, whereas the demand for oil is used here. Although there is no necessary relation between the size of the own price elasticities of the demand for energy and oil, it would be reasonable to suppose that oil demand is more elastic than all energy demand. On the other hand, the studies for transportation (where use is virtually all petroleum based) obtain roughly the same estimates as those referring to demand for total energy.

A second estimate for the value of the substitution parameter is obtained by examining behavior during the sample period. If the substitution parameter in equation 2 is fitted freely, the following set of estimates is obtained as a function of the lag parameter on the left-hand side of equation 2 :

Lag parameter $(1-\delta+a-g)$ (percent per year) Elasticity of substitution

95.0

90.0

85.0

80.0

These estimates confirm that the choice of 0.8 for a substitution parameter is consistent with behavior of oil demand in industrial countries for the past two decades.

Another major component of the macroeconomic model is a set of three equations that determines the rate of inflation. First, a cost equation defines the level of unit prime costs:

$$
\text { Cost }_{t}=\frac{3.16\left(\text { Cpoil }_{t}\right)\left(\text { Oil }_{t}\right)\left(\frac{Q_{t}^{*}}{Q_{t}}\right)+W_{t} E_{t}^{*}}{Q_{t}^{*}},
$$

where Cost $_{t}$ is the normal unit cost of production in year $t$. 
A second, behavioral, equation determines the rate of wage inflation. Because wage inflation is assumed to be inertial, if price inflation does not change and if unemployment is at the natural rate, inflation does not change. The natural rate for the OECD countries is taken to be equal to the average unemployment rate for the historical period, 3.25 percent. Given these assumptions, the wage equation becomes

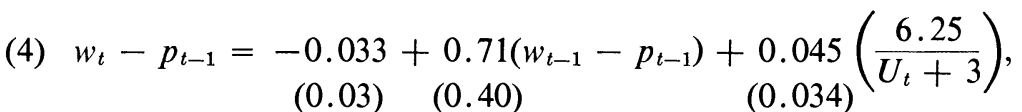

$$
\bar{R}^{2}=0.63 ; \text { Durbin-Watson }=2.2 ; \text { standard error }=0.0155 \text {. }
$$

where $w_{t}$ is the rate of wage growth and $p_{t}$ is the rate of price inflation.

The final relation in the price-wage sector is the price equation. Price is assumed to be a markup over unit prime cost (the variable Cost $_{t}$ defined in equation 3 above). In addition, however, higher utilization (for example, if actual output rises above potential) may change the markup. The final equation is

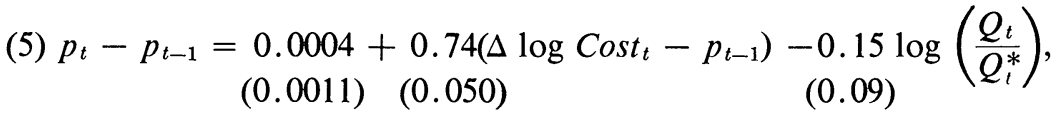

$$
\begin{aligned}
& \bar{R}^{2}=0.98 \text {; Durbin-Watson }=2.1 \text {; standard error }=0.005 \text {. }
\end{aligned}
$$

Taken as a whole, the wage-price subsector resembles results presented in earlier articles in Brookings Papers. ${ }^{21}$ Wage inflation for the OECD as a whole does respond in a modest way to unemployment. Beginning at the natural rate, with unchanged inflation, a 1.0 percentage point increase in the rate that is sustained for one year produces a deceleration of 0.6 percent in wage inflation in the first year and 2.0 percent deceleration in the long run. If prices and wages both adjust, a 1.0 percent increase in prices-such as through an oil-price shock-will lead to a 0.2 percent increase in nominal wages in the following year and a 2.0 percent increase in the price level after seven years. The reaction of wages to unemployment is somewhat higher than for the same specification for the United

21. Jeffrey D. Sachs, "Wages, Profits, and Macroeconomic Adjustment: A Comparative Study," BPEA, 2:1979, pp. 269-319; George L. Perry, "Determinants of Wage Inflation around the World," $B P E A, 2: 1975$, pp. 403-35; Robert J. Gordon, "World Inflation and Monetary Accommodation in Eight Countries," BPEA, 2:1977, pp. 409-68. 
States alone; indeed, it is generally thought that regions outside the United States do have greater wage response to both price and unemployment. ${ }^{22}$

\section{ENERGY SECTOR}

The energy sector focuses on petroleum as the chief fuel, with equations for demand and supply and an equation for clearing the market. The major novelty in the approach is the adjustment mechanism for clearing the market - the operation of the cartel.

The model concentrates on the oil market alone, although a more appropriate treatment would clearly include natural gas and abundant energy sources (coal and nuclear power). Because the share of resource rents in total costs is extremely low for all fuels except natural gas and oil, there is unlikely to be a major bias in the estimates of substitution behavior by confining the model to the oil market. Moreover, if there had been significant substitution of nonoil fuels for oil fuels, this fact would be reflected as a higher estimated elasticity of substitution between oil and labor (or as a higher price-elasticity of the demand for oil). The fact that the unconstrained estimated elasticity is very close to 0.8 indicates that the estimates used here are not strongly biased.

The demand for oil is derived from equations 1 and 2 above. A 10 percent shock, or sudden increase in the relative price of energy to nonenergy inputs, will lead to an 8 percent decrease in the ratio of oil to labor inputs in new capital goods. If new capital is one-tenth of the capital stock, the overall change will be only 0.8 percent in the oil-labor ratio. But as the share of the postshock capital increases, the response of energy demand to the price shock also rises.

The supply side of the oil market is extremely simple. The model divides oil supply into OECD domestic production and OPEC supply. In both cases, productive capacity is assumed to be completely price inelastic during the period examined. This assumption has a different rationale for the two sources of supply. For the OECD, the assumption of complete

22. One significant difference between this specification and others arises because the lag of inflation in the wage equation produces a very low feedback between price shocks and wage inflation. In many studies (see note 21 ), the coefficient on inflation is closer to 1.0 than to the 0.3 estimated here. To guess at the sensitivity of the results to this specification, I introduce later an alternative wage equation that does not lag inflation; such an equation has a coefficient of 0.8 on prices but is probably biased upward because of simultaneity. 
inelasticity is surely too pessimistic. The medium-term Department of Energy model estimates that the elasticity of production in 1990 and 1995 with respect to net producer price in the previous ten years will be 0.2 , a number not out of line with other studies. ${ }^{23}$

Some care must be given in modeling such a supply response: a simple supply function will not suffice because it is not clear that higher taxes or prices will accrue to domestic producers. The 1980 U.S. windfall profits tax plus corporation tax and royalties capture between 30 and 90 percent of increases in the oil price throughout the world, so the effective price increase to producers is much smaller than the increase in the market price. ${ }^{2 \pm}$ The 0.2 price elasticity figure implies that a doubling of world oil prices would, after ten years, lead to between a 2 and 11 percent increase in production. Moreover, many of the energy policies modeled herewhich may or may not actually lead to higher consumer oil prices-almost never lead to higher producer prices. Of the U.S. policies listed above, only import tariffs (which were twice imposed by presidents and twice rejected by Congress) lead to higher domestic producer prices. The production of unconventional fuels (heavy oils, shale oil, or liquified coal) is probably much greater in the long run and such fuels are likely to receive market prices; but the lags are even longer than for conventional production. In the period under examination here, to 1990 , the supply response is likely to be minimal. ${ }^{25}$

To introduce a domestic supply response into the model, it is only necessary to increase the elasticity of substitution. Thus, with the assumptions that half of energy tax increases are of a sort that increase domestic producer prices, that the ratio of retail to wholesale prices is 2.5 , and that the effective tax rate on domestic oil income is 50 percent, the elasticity of substitution could then be increased from 0.80 to 0.82 . This approach is probably a reasonable approximation for the period between now and

23. See Department of Energy, Energy Information Administration, Annual Report to Congress 1979, vol. 3, DOE/EIA-0173(79)/3 (DOE, 1979), p. 298.

24. A discussion of the structure of the windfall profits tax and its effect on production is contained in Philip K. Verleger, Jr., "An Assessment of the Effect of the Windfall Profits Tax on Crude Oil Supply," The Energy Journal (forthcoming).

25. The Department of Energy estimates that due to physical, environmental, and regulatory constraints, the upper limit of synthetic liquids for 1990 is $0.30 \mathrm{mmpd}$. The middle-term projection, with an oil price increase similar to the baseline run below, shows production in 1990 of 0.25 mmbd of synthetic liquids (see EIA Annual Report to Congress, 1979, pp. 122, 331). 
1990; after then, more detailed modeling of the energy sector is needed to estimate supply responses properly.

The supply side for the OPEC countries also assumes, as a first approximation, that their capacity does not respond to oil prices. Such an assumption appears to be relatively realistic-some might argue that it is optimistic. Outside Iran and Iraq, capacity in 1980 appears to be approximately the same as it was in 1973. The grand expansion plans of the early 1970s-projecting Saudi Arabian production of $26 \mathrm{mmpd}$ and Iranian output of $13 \mathrm{mmpd}$ by 1985 - have been rendered obsolete by revolution and oil price increases. In contrast to the United States, total drilling activity in major OPEC countries has not changed markedly since 1973, again suggesting that there is not a major OPEC capacity response to higher prices. ${ }^{26}$

The final element in the oil market is the mechanism that equilibrates demand and supply. In the oil model the contract market is separated from the spot market. The contract market, which has varied from 90 to 98 percent of the total oil market, represents normal trading channels. The remainder, the spot market, is a kind of buffer that absorbs-and, more fundamentally, reflects-underlying supply and demand shocks. ${ }^{27}$ In periods of excess supply, there will be discounts from the OPEC price on the spot markets, while during a shortage (such as the winter of 197374 or the $1979-80$ period) the spot market price lies well above the official price.

One of the key features of the world oil market that has received little attention is the relation between OPEC price increases and the spot market. All major OPEC price increases have come at a time when spot prices are far above the OPEC price. In November and December 1973 the spot price was $\$ 18.50$ a barrel, while marker crude sold for $\$ 5.11$ a barrel. Similarly, in the first half of 1979 the open-market price averaged $\$ 25$ a barrel, while the official price was only $\$ 14$. In the winter of 197374 OPEC doubled its official price, although the OPEC price was raised by 71 percent in 1980 over 1979 . On the other hand, during periods in which the spot price was near the official price, oil-exporting countries

26. Total well completions in the Middle East rose from 609 in 1973 to 644 in 1977. By comparison, the figures for North America were 32,600 and 52,900 for the same two years (see API, Basic Petroleum Data Book, table III.11).

27. For a useful discussion of the role of the spot market, see Joe Roeber, "Dynamics of the Rotterdam Market," The Petroleum Economist, vol. 46 (February 1979), p. 50. 
had great difficulties increasing prices. In fact, during years when the spot price was within 6 percent of the official price, there was no OPEC price increase of more than 9 percent.

It appears that, once the individual countries have made their production decisions, the main function of the OPEC cartel is to slow down the adjustment of oil prices; but this stickiness seems to be quite asymmetrical. In periods of excess demand, there is little OPEC can do to brake oil price increases. Individual countries can raise their prices without hurting sales, so the official price spirals up, chasing the spot price. In periods of slack, such as when spot prices fall below official prices, OPEC has succeeded in restraining official price cutting even with significant excess capacity. This argument does not rest on the quantitative importance of the spot market; rather, it treats the spot market as a thermometer for measuring the degree of tightness of world oil markets. If spot prices are well above list prices, even if a few transactions are occurring, this indicates that producers who are behaving noncooperatively will meet little resistance in raising their selling prices.

Reflecting these features of the oil market, the equilibration process is modeled as follows: when the oil market shows a glut, spot prices are below list prices and OPEC prices tend to be sticky. ${ }^{28}$ The adjustment to the glut is in building up consumer inventories or lowering OPEC production. In periods of shortage, spot prices shoot up above OPEC prices. As in most competitive commodity markets, list prices adjust upward to close the gap between spot and list prices.

The two features of the oil market that distinguish it from other commodity markets are the slow upward adjustment of prices, that is, OPEC closes only a fraction of the gap; and the great downward inflexibilityonce OPEC prices rise, they do not fall. These two features lead to a phenomenon of oil price ratcheting, by which positive shocks lead to an upward movement in oil prices, but downward shocks do not.

Two equations, one reflecting the spot price and the other the official

28. The model assumes that OPEC prices are sticky in nominal terms when there is a glut, and this is probably an accurate description of the 1973-78 period. Moreover, the key feature of the pricing mechanism for policy purposes is the "kink" shown in figure 4 rather than the nominal stickiness of prices. One should, however, be hesitant to forecast that nominal stickiness would continue in the future given widespread experience of institutions adjusting to inflation. Indeed, the long-term pricing strategy currently under consideration by OPEC includes quarterly indexing of OPEC prices to prices in industrial countries. 
price, are used in the model. The spot-price equation measures the discount or premium that exists in the spot market relative to the official OPEC price. It is extremely nonlinear; below a critical value (97 percent of capacity) it is assumed that the spot price sells at a fixed discount relative to the official price. Above the critical value (or kink), however, the supply function turns essentially vertical. Estimating the equation for the 1972-79 period yields

$$
\text { Spoil }_{t}=\text { Poil }_{t} \times\left\{\begin{array}{l}
0.977 \text { if } U t i l_{t} \leq 0.97 \\
0.430+0.543 g\left(U_{t i l}\right) \\
(0.06) \quad(0.04)
\end{array} \text { if } U t i l \geq 0.97,\right.
$$$$
\bar{R}^{2}=0.993 ; \text { Durbin-Watson }=2.2 \text {; standard error }=0.60 \text {. }
$$

where

$$
\begin{aligned}
\text { Spoil }_{t} & =\text { spot price of oil } \\
\text { Poil }_{t} & =\text { OPEC oil price } \\
\text { Util }_{t} & =\text { ratio of oil demand to oil capacity } \\
g(U t i l) & =5000(\text { Util }-0.97)^{2}+1 .
\end{aligned}
$$

Figure 4 presents data on the ratio of spot to the official price and the utilization rates for recent years, as well as the theoretical function fitted by equation 6.

The other equation in the oil market shows the extent to which the official OPEC oil price changes in response to differences between the official and spot price. This takes the form of a partial adjustment, with a 1974 dummy variable to represent the special effect of the oil embargo:

$$
\begin{gathered}
\text { Poil }_{t}-\text { Poil }_{t-1}=0.37\left(\text { Spoil }_{t}-\text { Poil }_{t-1}\right)+5.22 \mathrm{dum} 74 ; \\
(0.029) \\
\bar{R}^{2}=0.992 ; \text { Durbin-Watson }=1.4 ; \text { standard error }=0.46 .
\end{gathered}
$$

The equation states that in any year about one-third of the difference between the official and spot prices is closed by an OPEC price rise.

Although equations 6 and 7 seem to fit recent history extremely well, there can be little confidence in the quality of the fit. In only two years do crisis situations appear-1973 and 1979-so there are in effect several control years and two extreme observations. Moreover, the capacity figures are not firm data. These results nevertheless appear highly plausible and provide a good empirical basis for the historical simulations and policy analysis below. 
Figure 4. Ratio of the Spot to the Official Oil Price and Excess Productive Capacity, 1972-79a

Ratio of spot price to official price

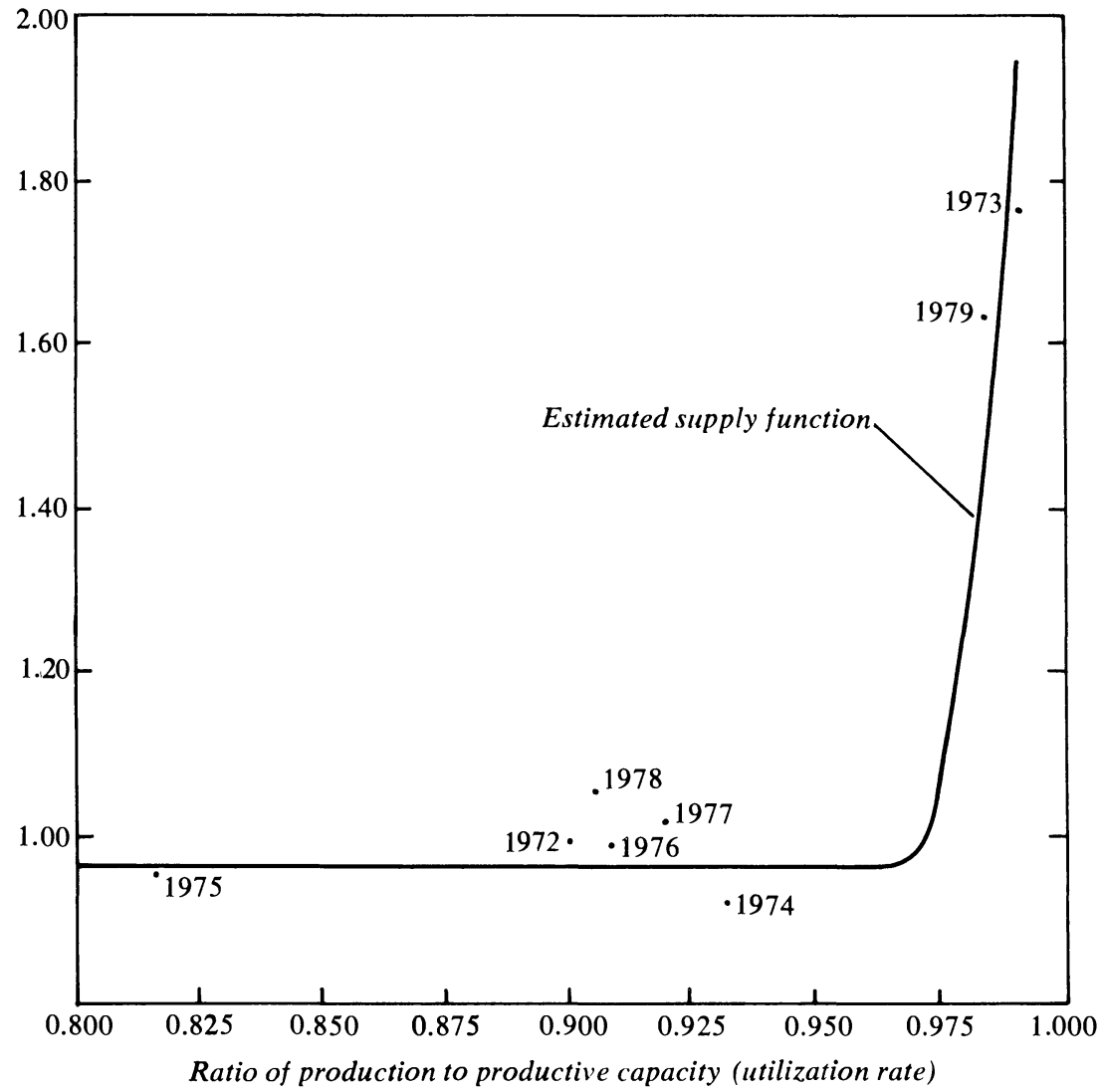

Source: Calculations by the author. A description of the sources and the data are available upon request to the author.

a. The denominator of excess capacity ratio is defined as the oil consumption of the OECD nations.

\section{POLICY REACTIONS AND THE OBJECTIVE FUNCTION}

The analysis from here on specifically allows for the behavior of economic policy. In all projections it is assumed that policies actually follow a behavioral reaction function. This function is estimated from past data. In addition, the value of an objective function is calculated to provide a way of comparing the outcomes of alternative policies.

The behavioral approach is necessary for estimating the historical ef- 
fects of past shocks or for projecting behavior in the future. It is assumed that the unemployment rate is the only instrument of macroeconomic policy. Further, in setting the unemployment rate, policymakers keep their eye on past values of both unemployment and inflation. The following estimated reaction function is used to project the behavior of policy in all simulations:

$$
\begin{gathered}
U_{t}=0.62+16.6 p_{t-1}+0.60 U_{t-1}, \\
(0.19)(2.3) \quad(0.07) \\
\bar{R}^{2}=0.96 ; \text { Durbin-Watson }=2.7 ; \text { standard error }=0.25
\end{gathered}
$$

In this policy reaction equation, if prices are stable, the unemployment rate objective is estimated to be 1.5 percent for the OECD as a whole, approximately one-half the estimated natural rate. For every percentage point of increase in steady-state inflation, however, the unemployment rate is increased by 0.4 percent. Given the price-wage assumptions, at the natural rate the equilibrium inflation rate is about 4.0 percent.

To evaluate the costs and benefits of alternative energy and macroeconomic strategies, I develop an objective function, or criterion, by which alternative policy choices can be ranked. The objective function to be maximized is the discounted value of "augmented real income." Real income is defined as conventionally measured real gross domestic product with a correction for terms-of-trade losses; future real income is discounted at the estimated after-tax rate of return on capital ( 6 percent a year); and augmented real income is defined as income with a correction for the costs of inflation. Note that projections of the future policy start with equation 8 even though the value of policies is determined by the technique I am now describing.

A major issue in the construction of the objective function is the correction for inflation in augmented real income. The treatment of inflation is one of the most unsatisfactory elements in most analyses of alternative policies. It is impossible to understand macroeconomic policies in industrial countries without recognizing that lower unemployment and lower inflation are both key objectives. More formally, policy can be described as maximizing an objective function that is, say, the discounted value of utility, where utility is a convex function of unemployment inflation. Such a maximization will lead to a policy response something like the behavioral ones estimated in equation 8 above.

The difficulty arises because there is, to my knowledge, no sensible 
utility function for which a simple reaction function can be written, and because all utility functions that provide simple reaction functions are implausible. For example, the much-used linear utility function predicts that there is no response of unemployment to inflation-a prediction that is clearly refuted by the historical behavior described in equation $8 .^{29}$

The inflation correction used here is obtained as follows. Assume the economy is initially on a base path with stable prices, and that a new path for the economy has an inflation rate that is 1 percent in 1975 and zero in other years. The first step is to calculate how much output would have to be reduced to extinguish the 1 percent inflation rate-say this means 1975 output must be reduced 3 percent. Augmented real income is then obtained by subtracting from real income the amount of output necessary to eliminate the inflation along the new path-here, augmented real income is 97 percent of real income for 1975. Such a procedure is approximately equivalent to taking the unemployment-output trade-off from the short-run Phillips curve as the "price" of inflation. The precise objective function used is

$$
\begin{aligned}
\text { Welf }= & \sum_{t=1980}^{2000}\left\{\left[Q_{t}-\left(\frac{\text { Poil }_{t}}{P_{t}}-\frac{\text { Poil }_{\gamma 2}}{P_{\gamma 2}}\right) \text { Imp }_{t}\right]\right. \\
& \left.\times\left[1-0.35 p_{t}\left(\frac{3+U_{t}}{6.25}\right)\right]\right\}(1.06)^{-t},
\end{aligned}
$$

where Welf is discounted augmented real income, and Imp is the real value of oil imports.

The optimizing approach has two convenient features. First, it allows the construction of an index of augmented real income that avoids the frequently encountered pitfall of ignoring the inflationary impacts of policies. Second, if the original path was close to optimal, the objective function will calculate the value of paths under alternative policies accurately to a first order of approximation.

\section{DATA AND METHODS}

The data for macroeconomic activity and oil production refer to the OECD or to the Summit Seven countries. All data on user oil price and

29. See Franco Modigliani and Lucas Papademos, "Optimal Demand Policies against Stagflation," Weltwirtschaftliches Archiv, vol. 114 (December 1978), pp. 736-82. 
consumption refer to the Summit Seven. For almost all data, these seven countries account for 85 percent of OECD production, employment, and energy consumption. The data on oil price are a composite of prices constructed from three sectors-transport, residential, and industrial-for the seven countries during the 1955-79 period. Oil consumption refers to the oil used as a final fuel for the same period.

National accounts data generally refer to the Summit Seven also. The exceptions are data on the labor force, employment, and wages, which cover the OECD as a whole. ${ }^{30}$

The equations were estimated with annual data for 1960-79 using ordinary least squares, except for the equations for oil price, which were estimated for 1973-79. A slightly different specification of the system was also estimated using more sophisticated techniques, but most performed badly in dynamic simulations for the sample period. Because of the simplicity of ordinary least squares, the decision was made to use that technique for all equations.

\section{Putting the Model to Work}

Having outlined the analytical background and empirical estimates of the MEPW, I now turn to its application. This section presents the behavior of the model in the sample period. The next section then reviews recent history and investigates what would have happened without the 1973 and 1979 oil crises. Next, the model parameters and conventional assumptions about the world oil market for the 1980s are used to forecast major economic variables for 1980 to 1990 . Finally, policy applications are suggested and questions raised about the effects of energy taxes and slower economic growth on the performance of industrial countries.

\section{MODEL BEHAVIOR IN THE SAMPLE PERIOD}

Both dynamic and nondynamic simulations of the model are run to determine how well it performs within the period of estimation (basically 1960 to 1979 ). In the dynamic simulations the model begins with the

30. A more complete description of the data is available from the author on request. 
Table 5. Summary Statistics for Selected Variables in Dynamic and Nondynamic Simulations, 1960-79a

\begin{tabular}{|c|c|c|c|c|}
\hline \multirow[b]{2}{*}{ Variable } & \multicolumn{2}{|c|}{ Dynamic simulation } & \multicolumn{2}{|c|}{ Nondynamic simulation } \\
\hline & $\bar{R}^{2}$ & $\begin{array}{l}\text { Root mean } \\
\text { squared error }\end{array}$ & $\bar{R}^{2}$ & $\begin{array}{l}\text { Root mean } \\
\text { squared error }\end{array}$ \\
\hline Unemployment rate (percent) & 0.760 & 0.65 & 0.950 & 0.23 \\
\hline $\begin{array}{l}\text { Potential output (billions of } \\
1975 \text { dollars) }\end{array}$ & 0.998 & 39.00 & 0.998 & 38.00 \\
\hline $\begin{array}{l}\text { Demand for oil (thousands of } \\
\text { barrels a day) }\end{array}$ & 0.988 & 730.00 & 0.992 & 940.00 \\
\hline $\begin{array}{l}\text { Rate of wage inflation (annual } \\
\text { average, in percent) }\end{array}$ & 0.460 & 1.90 & 0.680 & 1.50 \\
\hline $\begin{array}{l}\text { Rate of price inflation (annual } \\
\text { average, in percent) }\end{array}$ & 0.810 & 2.00 & 0.870 & 1.20 \\
\hline $\begin{array}{l}\text { Spot price of oil (doliars per } \\
\text { barrel) }\end{array}$ & 0.620 & 4.20 & 0.998 & 0.33 \\
\hline $\begin{array}{l}\text { OPEC price of oil (dollars per } \\
\text { barrel) }\end{array}$ & 0.900 & 1.70 & 0.998 & 0.35 \\
\hline
\end{tabular}

Source: Simulations by the author.

a. Dynamic simulations are those in which the model is estimated with residuals equal to zero and with all endogenous variables set at their predicted values. Nondynamic simulations are those in which all lagged variables are set at historical values, whereas current variables are solved for simultaneously. $R^{2}$ is the squared correlation coefficient of predictions relative to actual values.

1959 values of all variables but simulates using forecasted values of endogenous variables and the actual values of exogenous variables. In the nondynamic simulations the model is solved simultaneously for current endogenous variables, but actual historical values are used for the lagged endogenous variables in each equation.

Table 5 provides the basic statistics describing the fit of the seven stochastic equations in the simulations. For most variables the nondynamic equations perform quite well, but the quality of fit deteriorates considerably in the dynamic formulation. Some deterioration is expected given that the model was constructed with very little tinkering. Aside from the spot-price equation, virtually every equation has the same form in the final model as in the first. Although more experimentation would have improved predictions within the sample, under the procedure followed standard errors are more realistic and, perhaps, forecasts outside the sample are more robust.

The equations of particular interest are those for the energy sector. 
The forecasts for spot and official oil price indicate that the nondynamic forecasts track the actual path very closely. As noted above, however, this reflects the small number of observations. The dynamic simulations show how sensitive the outcome is to small changes in causal variables. They predict much more decline in real price in the late 1960s, forecast the 1974 price explosion relatively well, and project the lull in real oil prices in the 1974-78 period; but they completely miss the 1979 rise in oil prices. The reason for the 1979 error is that oil demand in the late 1970s is underpredicted by about 2 percent.

Besides indicating the general quality of the model, the simulations also show one disturbing feature of reality - the extreme sensitivity of the outcome to slight changes in some economic conditions. It is unsettling to find that, according to the model, the occurrence of events as significant as the oil crisis of 1979 can depend on the volume of the background noise in world energy markets.

\section{RETELLING HISTORY DURING THE OIL CRISIS}

What might have happened if the 1970s had not been constrained by a tight oil market? This question is motivated by the observation that 1973 was a watershed year for industrial economies in both overall economic behavior and in their energy markets. To what extent has the poor economic performance since 1973 been determined by the rising energy prices?

The absence of an energy crisis is defined as what would have occurred if no embargo had taken place, if the Iranian revolution had not happened, and if the supply of oil had continued to rise rapidly during the 1970s-in short, if demand was always to the left of the kink in figure 4. For simplicity, in this exercise real OPEC prices are taken to be constant at their 1972 levels.

Table 6 shows some selected results of simulations to examine the effects of the oil crisis. As might be expected, the crisis had a major effect on the oil market itself. Oil prices rise much less rapidly in the "no oil shock" case, and oil demand grows much more slowly than it did during 1963-73. Outside the energy sector, on the other hand, the effects of the oil shock are modest. The two macroeconomic variables on which the oil crisis is estimated have the greatest effect were inflation and real income growth. As a result of the crisis, inflation was almost two-thirds percentage 
Table 6. Estimated Effects of the Oil Crisis on Major Economic Variables, OECD Countries, Selected Periods, 1973-79a

Percent

\begin{tabular}{|c|c|c|c|c|}
\hline \multirow[b]{2}{*}{ Variable } & \multirow{2}{*}{$\begin{array}{r}\text { 1963-73, } \\
\text { historical }\end{array}$} & \multicolumn{3}{|c|}{$1973-79$} \\
\hline & & Historical & No oil shock & Difference \\
\hline GNP growth rate & 5.00 & 2.68 & 2.83 & -0.15 \\
\hline $\begin{array}{l}\text { Inflation (rate of change in } \\
\text { consumer prices) }\end{array}$ & 4.10 & 9.30 & 8.71 & 0.59 \\
\hline Unemployment rate & 2.80 & 4.70 & 4.50 & 0.20 \\
\hline Productivity growth rate & 3.90 & 1.66 & 1.80 & -0.14 \\
\hline Potential output growth rate & 5.20 & 3.44 & 3.55 & -0.11 \\
\hline $\begin{array}{l}\text { Rate of growth in real income } \\
\text { per worker }\end{array}$ & 3.80 & 1.38 & 1.79 & -0.41 \\
\hline Oil demand growth rate & 7.50 & -0.06 & 2.44 & -2.50 \\
\hline Rate of growth in real oil pric & & & & \\
\hline Producer & 2.00 & 21.50 & 0.00 & 21.50 \\
\hline Consumer & -0.80 & 10.50 & 3.90 & 6.60 \\
\hline
\end{tabular}

Sources: Calculations by the author based on sources on national data and several OECD publications. A detailed description of the sources and the data are available from the author upon request.

a. Labor data cover all OECD countries. The remaining data cover the Summit Seven. The rates of growth are annual averages.

point a year higher during the six years while real income per worker grew 0.5 point a year slower. ${ }^{31}$

Perhaps the most surprising result is that very little of the productivity slowdown can be attributed to the energy crisis. Potential output in the OECD slowed from an average annual growth rate of 5.2 percent in 196373 to 3.5 percent in $1973-79$. Of the 1.8 percentage points slowdown, only 0.11 point is attributed to the oil crisis. The effect on actual productivity growth is similar.

Finally, a comparison of the difference in real incomes (GNP minus terms-of-trade losses) with and without the oil crisis shows the OECD countries lost a total of $\$ 713$ billion in real income (in 1975 prices) over the 1973-79 period; this amounts to 2.9 percent of total real income.

31. This analysis stops before the full impact of the Iranian revolution has been felt. Following the revolution in fall 1978, spot oil prices rose above $\$ 30$ a barrel by late spring 1979. Yet the official oil price for 1979 was only $\$ 18.60$, and-by my estimate-consumer oil prices in 1979 as a whole rose only 18 percent above 1978 . Another 30 percent increase-to be felt in 1980-is probable before the full impact of the 1978-79 events is realized. In what follows, then, 1979 is an awkward year to choose for the end of period, but unfortunately the data end there. 
In summary, the simulations of the effects of the oil crisis indicate that only a small part of the macroeconomic ills are due to the oil crisis. The variables most affected were inflation and real incomes, while relatively little of the slowdown in productivity or potential output growth should be attributed to oil.

This analysis may in some ways understate the real effects of the oil crisis. The model of the inflationary process is more inertial than that contained in many models: the specification of the wage equation as one in which prices enter in lagged form leads to an estimated coefficient on prices that is low relative to the view that real wages are sticky in the short run.

To determine how sensitive the results for 1973-79 are to the specification, the extreme view was estimated by an equation that included inflation in the wage equation in unlagged form and without correction for simultaneity. This specification raised the coefficient on inflation from 0.3 to 0.8 . Rerunning the model for the 1973-79 period with and without the oil crisis provides another estimate of the effects of price shocks on inflation when real wages are almost rigid. Moreover, under the modified specification, the effect of the oil crisis on the inflation rate was twice that shown in table 6 ( 1.3 percentage points compared to 0.7 point). No other variables in table 6 changed markedly, which suggests that, although the results of the basic model may understate the potency of the wage-price spiral, it is unlikely that real variables will be greatly changed by a different specification of the inflationary process.

The present analysis may in addition omit the unique behavior that occurred in response to the oil crisis. Crisis here has been interpreted narrowly as a rise in real oil prices. While this view might be reasonable for the 1979 experience, it is undoubtedly inaccurate for the 1973-74 period. Policymakers, consumers, and firms in 1973-74 responded to the oil crisis as if it were an event that was something between a calamity and the end of the world. Consumers tightened their belts; firms cut investment plans. And policies were made in response to the first oil crisis that had significant effects beyond those attributable to the oil price increase alone: governments stepped on the economic brakes; oil prices were controlled; fuel efficiency standards were mandated; hurdles to construction of the Alaskan pipeline were quickly cleared. If these further behavioral and policy measures are included as "effects of the oil crisis," the overall impact would probably be substantially different from that estimated here. 
The 55-mile-per-hour speed limit reduced oil demand and productivity more than a cost-minimizing response would have implied. Put differently, the analysis estimated the effect of the oil crisis that would reasonably be expected to occur through economic channels alone. If the induced policy and behavioral responses could somehow be included, the estimates of the actual impact of higher oil prices might be greater. ${ }^{32}$

\section{Outlook and Risks for the 1980s}

The model is next used to project events in the industrial countries in the 1980s. This section is divided into two parts. The first provides a baseline projection of the major oil sector and macroeconomic variables; the second reviews some of the oil supply risks and asks what macroeconomic damage might occur in such situations. The following major assumptions are made in the projections.

- The labor force of the OECD is assumed to grow at 1.3 percent a year, the same as the rate for the 1970-79 period.

- The growth rates of potential output and potential productivity are assumed to be the same as the rate predicted by the estimated equation for potential output.

- Oil demand is determined by the production function estimated from the historical period.

- Oil supply is projected under two sets of assumptions: a "surprisefree" baseline assumption and a "disruption" scenario. The baseline assumption is an amalgam of current consensus forecasts of the different specialized energy forecasting units (the U.S. Department of Energy, the Central Intelligence Agency, and the International Energy Agency). It is generally thought that, if there are no further major disruptions, the curve characterizing oil supply available to OECD countries will be flat or decline slightly during the next ten years. The baseline forecast assumes, then, that total oil supply available to OECD countries will be $0.5 \mathrm{mmpd}$ below 1980 levels. This is likely to be comprised of declines in OPEC and OECD outputs, with increases in oil production of other countries. ${ }^{33}$

32. The policy responses in the United States were, to be generous, random. The control of oil prices from 1973 to 1976 probably slowed the reaction of the economy; after 1977 economic policy probably hastened the response of the private sector.

33. A sampler of medium-run forecasts includes Workshop on Alternative Energy Strategies, Energy: Global Prospects 1985-2000 (McGraw-Hill, 1977); U.S. 
- For the disruption scenario, the question is how pessimistic to be. A recurrent nightmare is revolution in Saudi Arabia leading to a replay of the Iranian chaos. As a concrete case, here a disruption in the Persian Gulf is assumed that gradually shuts down oil production in Saudi Arabia (currently approximately $10 \mathrm{mmbd}$ ). In this case free-world oil supply, and by assumption, the supply available to OECD countries, will decline about 2 percent annually from 1981 to 1990 as opposed to the constant supply assumed to be available under the baseline scenario. ${ }^{34}$ Imports to the OECD countries will decline more rapidly, from 17.6 to $12.8 \mathrm{mmbd}$ in 1990 , because domestic production is unaffected by the disruption.

- The baseline policy is one in which energy policy is unchanged. As noted above, the instrument of energy policy in the MEPM is domestic consumption taxes on oil; any "conservation" policies are taken at their tax equivalent. In the baseline policy run, oil "taxes" and oil margins in OECD countries are assumed to be constant at $\$ 16$ a barrel in 1980 (in 1975 prices ), and they remain at that level. ${ }^{35}$

- The most important assumption underlying the projections is that the economic structure during the 1980 s remains unchanged from that estimated for the 1960-79 period.

\section{THE BASELINE PROJECTION}

The important results of the baseline supply run are shown in the second column of table 7 . The 1980 s are projected to be a period of continued constraints imposed by the oil market on the overall economic

Congressional Budget Office, The World Oil Market in the 1980s: Implications for the United States (GPO, 1980); Central Intelligence Agency, The World Oil Market in the Years Ahead; Organisation of Economic Co-operation and Development, "The Oil Situation," OECD Economic Outlook, no. 25 (July 1979), pp. 56-65; and EIA Annual Report, 1979. To give some idea of the dispersion, estimates of the 1985 oil production in the free world in these references range from about 45 to 65 mmbd.

34. Is the disruption scenario too optimistic? The curtailment due to the Iraq-Iran war puts actual oil supply developments three years ahead of the assumed disruption scenario.

35. The term taxes in this paper refers to the gross oil margin, or the difference between the retail price and the producer price, and it therefore includes oil taxes, transportation, refining, and distribution costs; it also reflects price controls. Because most elements of the real gross margin other than taxes or subsidies are constant, it is natural to interpret changes in gross margins as taxes. Policy measures generally take the form of taxes or subsidies. 
Table 7. Projections under Baseline Supply and Disruption Supply Scenarios for Major Economic Variables, OECD Countries, 1979-90

Percent, except as noted

\begin{tabular}{lrrr}
\hline & & \multicolumn{2}{c}{ 1979-90, supply scenario } \\
\cline { 4 - 4 } \multicolumn{1}{c}{ Variable } & 1963-73, & Baseline & Disruption \\
\hline GNP growth rate & 5.00 & 4.54 & 4.43 \\
Inflation (rate of change in consumer prices) & 4.10 & 4.70 & 5.20 \\
Unemployment rate & 2.80 & 4.90 & 5.10 \\
Productivity growth rate & 3.90 & 3.02 & 2.92 \\
Potential output growth rate & 5.20 & 4.07 & 3.98 \\
Rate of growth in real income per worker & 3.80 & 2.94 & 2.69 \\
Oil demand growth rate & 7.50 & -0.50 & -2.10 \\
Rate of growth in real oil prices & & & \\
$\quad$ Producer & 2.00 & 7.80 & 14.70 \\
Consumer & -0.80 & 4.30 & 9.20 \\
Addenda: & & & \\
1990 world oil prices (1979 dollars per & & & \\
$\quad$ barrel) & & & \\
1990 real income (billions of 1975 dollars) & & 6,300 & 6,132 \\
\hline
\end{tabular}

Sources: Same as table 6.

performance of industrial countries. Given the lack of growth in oil supply, prices continue to rise rapidly. From 1979 to 1990, real consumer oil prices are estimated to rise by 4 percent annually. This compares with the actual decline in real consumer oil prices of 1 percent annually in the 1963-73 period and a rise of 11 percent annually in the 1973-79 period. Given the passive baseline energy policy, the rise in real producer prices continues during the $1980 \mathrm{~s}$ - growing 8 percent a year in real terms during the 1979-90 period, with the world oil price rising to $\$ 43$ a barrel in 1990 (in 1979 prices).

Because of the continued rise in the real price of oil, the balance-ofpayments drain and real income loss of industrial countries continue to mount. The value of oil imports (in 1979 prices) rises from $\$ 130$ billion in 1979 to $\$ 275$ billion in 1990 .

The macroeconomic performance of industrial countries in the baseline supply projection has an outlook for the 1980s slightly worse than that of the decade before 1973 . Potential output grows at only 4.1 percent 
annually because productivity growth is somewhat depressed by the need to economize on energy. Unemployment remains high, averaging 4.9 percent, in order to prevent inflation from getting out of control. Even so, inflation averages 4.7 percent during the decade of the $1980 \mathrm{~s}$.

One of the surprising features of the projections is that they show a sharp decline in inflation during the next decade. This reduction comes largely because of a massive increase in the OECD unemployment rate, to an average rate of about 5 percent for the 1980s. In the United States this would correspond to an average unemployment rate of 9 percent for the next ten years. If such a high figure is rejected as implausible, the projected inflation rate would be considerably higher.

Finally, real income during the 1980 s also shows poor performance for the industrial countries. As a result of slow productivity growth and continued deterioration in the terms of trade, real incomes per employer in OECD countries rise by about 3 percent annually. Overall, then, the relatively optimistic baseline supply projection anticipates a slight improvement over the outlook for the 1970s, without an improvement to levels of the 1960 s.

\section{DISRUPTION SCENARIO}

As noted above, the disruption scenario assumes that $10 \mathrm{mmbd}$ of world productive capacity is removed gradually during the $1980 \mathrm{~s} .{ }^{36}$ The basic projections, shown in the third column of table 7 , are somewhat grimmer than they were for the baseline case. Producer oil prices rise at about 15 percent annually in real terms to 1990 , reaching $\$ 85$ a barrel (in 1979 prices). Consumer oil prices also grow much more rapidly, at 9 percent a year for the 1979-90 period. Inflation and unemployment are fractionally higher. Productivity and output growth are 0.1 percentage point lower over the eleven-year period. Finally, annual growth in real income per worker or per capita is slowed by 0.3 percentage point, so that 1990 real income in OECD countries is $\$ 168$ billion below the baseline case.

In sum, the disruption case shows considerably tighter oil markets during the $1980 \mathrm{~s}$, and there is a modest slowdown in macroeconomic performance. As noted above, these projections are "pure economic outcomes"

36. A simulation in which the $10 \mathrm{mmbd}$ was removed in a single year was also tried. The model did not converge for this case. 
and do not include any losses as a result of market disruptions (such as standing in line for gasoline) or irrational policy actions (such as lowering speed limits to 30 miles an hour).

\section{Alternative Energy Policies}

The final issue to examine is the effect of alternative energy policies on economic performance in industrial countries. The discussion below considers both policies that act directly on the energy market through higher oil prices and policies that act through influencing the level of macroeconomic activity. The following specific scenarios are analyzed.

Slow economic growth-Policy deliberately raises unemployment and slows economic growth in order to lower the demand for energy and take pressure off world oil markets. The policy gradually raises the target unemployment rate in equation 8 , beginning with an additional 0.3 percentage point and ending with an additional 3.0 percentage points in 1990 . Such a policy lowers GNP relative to the baseline policy path by 4 percent in 1985 and 6 percent in 1990.

Energy taxes-Energy sector policies are introduced by raising the user price of oil through taxes on oil consumption. The fiscal impacts of the oil taxes are assumed to be neutralized, except insofar as the higher inflation leads, through the policy reaction function, to a lower aggregate demand target. It is assumed that the taxes are recycled through lower income taxes, so that no offset to their price-raising effects occurs. Three specific policies are analyzed: a low tax in which oil taxes are raised by $\$ 1$ per barrel a year above the baseline run, reaching $\$ 32$ per barrel in 1990; a medium tax in which oil taxes are raised $\$ 4$ per barrel a year above the baseline run, reaching $\$ 62$ per barrel in 1990; and a high tax in which oil taxes are raised by $\$ 8$ per barrel a year, reaching $\$ 102$ a barrel in 1990 (all in 1979 prices).

Table 8 presents, for the baseline supply scenario, the results for the major economic variables in each of the four policy simulations and compares them with the baseline policy run.

In the oil market there are substantial differences among policies in both the consumer and producer prices of oil. Slow growth leads to slightly lower 1990 oil prices than the baseline policy case. Compared with baseline policy, the consumer price of oil is affected only slightly by 
Table 8. Projections for Major Economic Variables under the Baseline Supply Assumption, with Selected Alternative Policies, OECD Countries, 1979-90

Percent, except as noted

\begin{tabular}{|c|c|c|c|c|c|}
\hline \multirow[b]{3}{*}{ Variable } & \multicolumn{5}{|c|}{ Policy } \\
\hline & \multirow{2}{*}{$\begin{array}{l}\text { No policy } \\
\text { change }\end{array}$} & \multirow{2}{*}{$\begin{array}{l}\text { Slow } \\
\text { growth }\end{array}$} & \multicolumn{3}{|c|}{ Oil tax } \\
\hline & & & Low & Medium & High \\
\hline $\begin{array}{l}\text { Inflation (rate of change in } \\
\text { consumer prices) }\end{array}$ & 4.70 & 3.20 & 4.70 & 4.90 & 5.30 \\
\hline Unemployment rate & 4.90 & 6.00 & 4.90 & 4.90 & 5.20 \\
\hline Productivity growth rate & 3.02 & 2.78 & 3.02 & 2.98 & 2.89 \\
\hline Potential output growth rate & 4.07 & $3.53^{\mathrm{a}}$ & 4.07 & 4.03 & 3.97 \\
\hline $\begin{array}{l}\text { Rate of growth in real income } \\
\text { per worker }\end{array}$ & 2.94 & 2.56 & 3.00 & 3.09 & 3.02 \\
\hline Oil demand growth rate & -0.50 & -0.50 & -0.50 & -1.20 & -2.40 \\
\hline Rate of growth in real oil prices & & & & & \\
\hline $\begin{array}{l}\text { Producer } \\
\text { Consumer }\end{array}$ & $\begin{array}{l}7.80 \\
4.30\end{array}$ & $\begin{array}{l}7.00 \\
3.80\end{array}$ & $\begin{array}{l}5.40 \\
4.40\end{array}$ & $\begin{array}{r}-0.70 \\
6.30\end{array}$ & $\begin{array}{r}-1.50 \\
10.20\end{array}$ \\
\hline Addenda: & & & & & \\
\hline $\begin{array}{l}1990 \text { producer price (1979 dollars } \\
\text { per barrel) }\end{array}$ & 42.70 & 39.20 & 33.30 & 17.20 & 15.80 \\
\hline $\begin{array}{l}1990 \text { user oil price (1979 dollars } \\
\text { per barrel) }\end{array}$ & 64.40 & 61.00 & 65.00 & 79.00 & 117.60 \\
\hline $\begin{array}{l}1990 \text { real income (billions of } \\
1975 \text { dollars) }\end{array}$ & 6,300 & 5,869 & 6,340 & 6,400 & 6,300 \\
\hline
\end{tabular}

Sources: Same as table 6.

a. Assuming that 1990 actual GNP is equal to potential GNP.

the low tax but rises 2 percentage points a year faster with the medium tax and 6 percentage points a year faster with the high tax. The real OPEC price moves in the opposite direction from the tax, rising substantially to 1990 for the baseline, slow-growth and low-tax policies, and declining slightly in real terms with the medium or high tax.

One important policy issue is whether oil taxes are inflationary. The low-tax run produces little change in the growth of the real user oil price and therefore has an inflationary path close to the baseline policy. The average inflation rates are 0.2 and 0.6 percentage point higher for the medium- and high-tax cases, respectively. A good part of the first-round inflationary impact of the oil tax is offset because of lower producer prices. By contrast, slow growth and high unemployment eventually beat down inflation, but at a high price. 
There is no change in growth of potential in the low-tax case (because user prices do not change markedly). Potential growth is slowed by 0.04 percentage point a year with medium taxes and by 0.13 point a year with high taxes. These changes are small, but they add up over the decade. They illustrate one of the paradoxes about sensible energy policy: it lowers productivity. Thus the medium-tax run, which turns out to be the preferred path from the point of view of maximizing augmented real income, shows potential output in 1990 that is $\$ 25$ billion (or 0.5 percent) lower than that of the baseline policy. The slightly slower productivity growth in this case results from substituting domestic capital and labor for imported oil beyond the point that would be indicated by private cost minimization alone. Such an "inefficient" policy is worthwhile because of the income gains from the improved terms of trade in high-tax policies.

The results would differ somewhat if economic agents had perfect foresight about future price trends. In the present model, decisions about inputs of labor and energy are determined by current relative prices. If energy prices are rising rapidly, firms will regret their myopia. With perfect foresight, firms would anticipate future price trends and build more energy-efficient vintages. Such a result implies that tax policies that tilt the trajectory of real oil prices upward will lead to a prompter response than under myopic expectations. Note, on the other hand, that if higher taxes shift rents from producer to consumer countries rather than raise real prices, the assumption about expectations will not markedly change the economic value of energy tax policies.

In table 9 the alternative policies are compared using the overall level of the objective function, discounted augmented real income, for the entire period.

The slow growth path proves to be the worst way to solve the energy problem. Even though the rise in world oil prices is slowed by almost 1 percent a year in this case, the loss in output outweighs the gains in terms of trade. The 1990 level of real income in the slow-growth case is 7 percent below the baseline policy case; discounted augmented real income is almost $\$ 1$ trillion lower. Stringent energy taxation, on the other hand, appears to be an extremely productive way to increase real incomes. Compared with the baseline policy, discounted augmented real income is $\$ 400$ billion higher with low taxes, $\$ 900$ billion higher with medium taxes. The high-tax case overshoots the mark and leads to a lower level of discounted augmented real income.

The bottom half of table 9 shows the effects of the different policies 
Table 9. Estimated Overall Level of Economic Performance under Baseline and Disruption Supply Assumptions with Selected Alternative Policies, 1979-90 Billions of 1975 dollars

\begin{tabular}{|c|c|c|c|c|c|}
\hline \multirow[b]{3}{*}{ Supply assumption } & \multicolumn{5}{|c|}{ Policy } \\
\hline & \multirow{2}{*}{$\begin{array}{l}\text { No policy } \\
\text { change }\end{array}$} & \multirow{2}{*}{$\begin{array}{c}\text { Slow } \\
\text { growth }\end{array}$} & \multicolumn{3}{|c|}{ Oil tax } \\
\hline & & & Low & Medium & High \\
\hline \multicolumn{6}{|l|}{ Baseline supply } \\
\hline $\begin{array}{l}\text { Total discounted aug- } \\
\text { mented real income }\end{array}$ & 66,257 & 65,302 & 66,672 & 67,195 & 66,584 \\
\hline $\begin{array}{l}\text { Difference from no polic } \\
\text { change }\end{array}$ & $\cdots$ & -955 & 414 & 937 & 326 \\
\hline \multicolumn{6}{|l|}{ Disruption supply } \\
\hline $\begin{array}{l}\text { Total discounted aug- } \\
\text { mented real income }\end{array}$ & 65,194 & 63,996 & 65,518 & 66,257 & 66,584 \\
\hline $\begin{array}{l}\text { Difference from no polic } \\
\text { change }\end{array}$ & $\ldots$ & $-1,198$ & 324 & 1,063 & 1,390 \\
\hline
\end{tabular}

under the disruption scenario. The slow-growth policy is slightly more inefficient than it was in the baseline-supply case. Tax policies are even more attractive in the disruption scenarios because there are more rents from high oil prices to struggle over. There is also a different ranking of the tax policies: the high-tax policy appears to be best in the disruption scenario, adding approximately $\$ 1.4$ trillion to income. Moreover, the marginal value of the medium-tax over the low-tax run is $\$ 740$ billion for the disruption case compared to $\$ 520$ billion for the baseline supply scenario. These differences confirm our intuition that high taxes are more useful in scenarios with a more stringent supply constraint.

What is the overall cost of disruption? The estimates from the baseline supply and disruption supply scenarios runs provide a measure of the "macroeconomic cost of oil" to the OECD countries. The macroeconomic cost of oil is defined as the cost, in terms of discounted augmented real income, of reducing supply or increasing demand for oil. ${ }^{37} \mathrm{~A}$ comparison

37. A formal definition of the macroeconomic cost of oil is given in William D. Nordhaus, "The Macroeconomic Cost of Microeconomic Shocks: The Case of Oil," paper presented to the 1980 annual meeting of the American Economic Association. 
of the baseline policy runs for the baseline and disruption supply scenarios shows that discounted augmented real income is $\$ 1,063$ billion lower while discounted oil consumption is 12.7 billion barrels lower in the disruption scenario. This suggests the macroeconomic cost of oil is $\$ 84$ a barrel above the market price for this period.

A final aspect of energy policies concerns their direct inflationary impacts. All energy policies have been modeled in price-equivalent terms. Although in some cases this is accurate, many policies-particularly regulatory ones-do not affect consumer prices of energy. To what extent is there a premium on energy policies that do not raise energy prices?

To investigate the use of shadow taxes as a substitute for taxes, the model is modified by using the revenues of oil taxes to lower other prices. This can be interpreted as either recycling the energy taxes through subsidies on other products, or as using regulatory policies rather than tax policies. Shadow taxes of $\$ 10$ a barrel thus have the same effect on the substitution of capital and labor for energy as a real tax of $\$ 10$ a barrel; they do not raise costs, however, and do not affect inflation.

The effect of energy taxes that do not increase prices was investigated for the three types of tax policy and both baseline and disruption supply scenarios. The premium on the use of policies that do not increase prices is calculated by comparing the discounted augmented real income from such policies with the corresponding incomes in table 9. For the baselinesupply, low-tax case, the gain in discounted augmented real income is $\$ 482$ billion with shadow taxes and $\$ 414$ billion with taxes-a gain, or premium, of 17 percent. The percentage premiums for all cases are as follows.

\begin{tabular}{ccc} 
& \multicolumn{2}{c}{$\begin{array}{c}\text { Premium on the use of nonprice-raising } \\
\text { energy taxes (percent) }\end{array}$} \\
\cline { 2 - 3 } Policy alternative & Baseline supply & Disruption supply \\
Low tax & 17 & 18 \\
Medium tax & 40 & 24 \\
High tax & 201 & 42
\end{tabular}

There is in all cases a significant improvement from policies that do not raise prices, with the premium ranging between 17 and 201 percent in the baseline supply case and from 18 to 42 percent in the disruption case. For the best tax in each case, the shadow-tax premium is about 40 percent of the welfare gain from a tax policy. Put differently, if the tax revenues of 
oil taxes cannot be recycled so as to offset their effects on the price level, the value of energy taxes in the best cases is reduced by one-third.

When the three tax policies are ranked depending on whether they are tax or shadow tax, one can see that the ability to use shadow-tax policies should lead to more stringent policies. In both the baseline supply and the disruption cases, the medium- and high-tax alternatives are more attractive than the low tax alternative when the revenues can be recycled. In neither case, however, does the best of the three options change; the optimal shadow tax remains the medium one in the baseline case and the high one in the disruption case. This result suggests that it would be a serious error to avoid or postpone the steep oil taxes because of fears of their inflationary impacts.

\section{Conclusions}

This investigation of the value of policies of slowing overall economic growth and imposing high energy taxes on industrial economies indicates that it would be a mistake to slow economic growth as a way of alleviating constraints on energy supply. The loss in discounted augmented real income of the slow-growth policy that is assumed here is on the order of $\$ 1$ trillion. On the other hand, it appears that a policy to reduce oil consumption through high oil taxation in industrial countries would be highly beneficial. Three oil tax scenarios were examined corresponding to increasing real consumer oil taxes per barrel by $\$ 1, \$ 4$, and $\$ 8$ a year. For both an optimistic and pessimistic supply assumption, each of these oil tax policies increases the real income of industrial countries. It appears that the medium tax is the best for the optimistic supply scenario while the high tax is best for the pessimistic scenario. The overall economic gains that arise from the oil taxes appear to be extremely large, ranging from about $\$ 400$ billion for the low tax to $\$ 1,400$ billion for the high tax in the disruption case.

The analysis of the effects of high oil taxes provides an economic rationale for energy policies in consumer countries. The fundamental logic of energy policies is to take actions that are the economic equivalent of tariffs on imported oil, lowering the demand for imported oil and thereby relieving pressure on world oil markets. If the supply of oil on world markets is inelastic_-as I have argued-in the long run the lower demand 
for oil will produce lower world oil prices, lower terms-of-trade losses, and higher real incomes of consuming countries. Although I have not calculated the "optimal tariff" on imported oil, a rough guess would be that it lies between $\$ 25$ and $\$ 50$ a barrel above current taxes; the exact amount depends on the timing and supply assumptions.

A word of caution is in order about the policy runs presented here. These policies and simulations should be taken as pure polar cases, almost as parables. Realistic features of economic and energy policy could make policies less attractive than the polar cases. Three particular caveats are important. First, the analysis assumes that no retaliation by oil producers occurs in response to energy policies. Such a view is based on the above analysis that oil producers are, particularly over the long run, effectively in noncooperative equilibrium and that there is currently little scope for cooperative price raising. Such a view could prove to be wrong, in which case, with retaliation, higher prices and a more complicated oil supply situation would result than anticipated in the simulations.

Second, OECD countries may not act in concert in imposing "optimal" oil taxes. There are, unfortunately, few cases in which industrial countries have taken cooperative action beyond that which they would take in their own self-interest. If each country did act in its own selfinterest (in parallel with the assumption in my analysis about OPEC countries), the size of the tariff would probably be smaller than today's level of oil taxation. ${ }^{38}$

Third, the model may oversimplify reality by modeling every policy as oil taxes and by assuming efficient recycling of the oil taxes. Experience in the United States shows that at least a fraction of the revenues will be devoted to marginal uses (gasohol being perhaps the most inefficientindeed, counterproductive-use on record). If the tax revenues are completely wasted, then to a first approximation there is no gain from the tax-based energy policy. Put differently, the gain from high energy taxes arises because the revenues are domestic income rather than foreign income. If the domestic income is not turned to useful purposes, the potential gain is wasted.

38. For example, assume that the marginal cost of higher oil taxes is linear in the tax rate while the marginal benefit is proportional to the square root of the tax rate. Costs are national, and the benefits received are proportional to net oil imports. Restricting the analysis to the Summit Seven, if the optimal cooperative tax is $\$ 30$ a barrel, the average consumption tax in the noncooperative case is $\$ 3.20$ a barrel. If other countries are included, the equilibrium noncooperative tax is even lower. 
At the same time, not all uses of the revenues would be wasteful relative to the recycling envisaged here. One way in which alternative policies would be more efficient than straight recycling is if the tax revenues are recycled in ways that lower prices, such as through subsidies, tax credits, or lower value-added or social insurance taxes. In these cases the inflationary side effects of oil taxes would be reduced. Another approach to improving the effectiveness of oil taxes would be to recycle the oil taxes through lower taxes on labor and capital. Today many analysts feel that there would be large supply-side effects from lowering factor taxes because the lower taxes would stimulate the supplies of capital and labor. Whatever the validity of these views, it would certainly be a step forward if governments raised a smaller fraction of necessary revenues by taxing activities we want to encourage (supply of capital as well as production of useful goods and services) and a larger fraction by taxing goods we want to discourage (pollution or oil consumption). 


\section{Comments and Discussion}

Hendrik S. Houthakker: The great merit of this paper is that it asks many of the right questions, and thanks to the author's underlying good sense, it comes up with some of the right answers. As a piece of empirical research, however, it leaves considerable room for improvement. William Nordhaus writes like a man in a hurry, impatient with theory and casual about econometric methods, but intensely interested in policy conclusions. What we have here is essentially the back of one of his envelopes. Although I prefer his first drafts to many a lesser man's finished product, I would have been much happier with his finished product, for which we will presumably have to wait until his book with Edward Buffie is published.

I shall not say much about the energy-macroeconomic model. It is sophisticated in some of its microeconomics, particularly in its recognition of the role of capital and its analysis of price formulation in the oil market. The macroeconomics, on the other hand, comes largely from an earlier and more confident era when most of us believed in well-behaved Phillips curves in both the short and long run. That treatment of Phillips curves is not consistent with what I found for the United States (in my 1979 paper $)^{1}$ and for several other countries. The reasoning underlying certain other parts of the model is unfortunately not clear to me; thus the main argument in favor of assuming that the supply elasticity of energy is zero appears to be that elasticity is about 0.2 for the United States-if so, why not use 0.2 ?

One could overlook these theoretical defects if the empirical results were convincing, but several of the equations can hardly be described

1. Hendrik S. Houthakker, "Growth and Inflation: Analysis by Industry," $B P E A$, 1:1979, pp. 241-56. 
that way. Perhaps the worst example is the energy-demand equation (2). Apart from the intercept the only estimated coefficient is that of time, which is not statistically significant. Yet the equation also contains a second trend term beginning in 1973 and a dummy variable for 1973. The author explains that these equations were not revised after the first attempt, but why did he introduce this panoply of gimmicks to begin with? Much the same applies to the productivity equation (1).

Despite these objections the model does produce some sensible results in simulation and projection. I was predisposed to believe that a deliberate slowdown in overall growth is a disastrous response to the oil problem, whereas moderate taxes on energy use provide considerable benefit. Neither did I have any previous difficulty in accepting the message of table 6, which is that the "oil crisis" was a less important event than many appear to think. It is perhaps reassuring that the Nordhaus model also leads to these conclusions.

While most of this paper is inevitably devoted to the model, there is actually more solid meat in the first part of the paper, which addresses the world oil market. Two issues there call for some comment; the first is oil discoveries. Nordhaus expresses disappointment with recent addition to reserves in the face of much higher prices. I understand his disappointment, but would put more weight on data problems than he does. The fact is that new discoveries do not become reflected in the generally used reserve data until some years after they are made. Prudhoe Bay, for instance, was discovered in 1967 but included in reserves only in 1970. Just today an apparently important discovery was reported in the U.S. sector of the Beaufort Sea; it will be interesting to see when this discovery, which was actually made in the winter of $1978-79$, is incorporated into the official data on reserves. One reason for these statistical delays is simply that it often takes considerable time and effort to establish proved reserves. It is not surprising, therefore, that the recent upsurge in U.S. drilling has thus far failed to yield large additions to reported reserves. Incidentally, Nordhaus' calculations would have been more meaningful if he had related discoveries to new field exploratory wildcats rather than to total drilling, and if he had aggregated gas and oil. Because small wells are now much more profitable than they were nineteen years ago, there has naturally been a sharp increase in the development of such wells.

At this point a reference to the 1973 paper by Nordhaus may be in 
order. ${ }^{2}$ In that seminal paper he taught us, among other things, that in the long run it is the "backstop technology" that matters. Since 1973 oil prices have risen much more than I or Nordhaus or anybody else expected. Does this mean that we have now come close to the price at which some backstop technology becomes competitive? If so, the concern about inadequate oil discoveries would be largely irrelevant. Although it is not at all certain that energy prices have reached the level just mentioned, it is at least conceivable. The exploitation of the Athabasca tar sands and of the Lloydminster heavy oil is already very profitable, but is held back by Canadian domestic politics. For obvious reasons, Venezuela is also going slow in the development of the Orinoco heavy oils. The conversion of coal into oil or gas, however, appears to be attractive at present prices. These backstop technologies require at least a decade or two to become an effective constraint on oil prices, but to some extent they may cast their shadow ahead. This makes the projections of oil price at the bottom of table 8 less plausible.

The last observation is also pertinent to the last topic in the paper that I shall address. This is the nature of OPEC, which has confounded many observers. With two of its leading members currently at war with each other, the cartel is evidently not what it once was. However, the cartel is not dead, as Nordhaus recognizes. It was perhaps never as strong as was widely believed, and its members may have benefited more from extraneous events (such as the fall of the shah of Iran) than from deliberate restrictions of output. The point on which I disagree mildly with Nordhaus is in his emphasis on noneconomic determinants of the behavior of cartel members. No doubt "survival of the monarchy" and the like are important concerns in some OPEC countries, but how can the same concerns lead Kuwait to curtail oil output and Saudi Arabia to increase it?

The explanation of this divergent behavior, I submit, is primarily economic. Unlike Kuwait and most other OPEC members, Saudi Arabia has vast oil reserves, probably much larger than published estimates. Moreover, the country does not have much except oil. This is why it has to take a longer view than other cartel members. Its concern is that in the twenty-first century the industrial countries will have developed high-cost but domestic (and probably protected) energy sources to the point that

2. William D. Nordhaus, "The Allocation of Energy Resources," BPEA, 3:1973, pp. 529-69. 
oil has gone the way of indigo or guano. This is why Saudi Arabia resists the get-rich-quick pressures of some less well-endowed cartel members. I am not denying that, in addition, Saudi Arabia's policy may occasionally reflect more strictly political considerations.

As usual, Nordhaus has given us much to think about. Although I wish he had brought his empirical work closer to completion, we must be grateful for the insights that are scattered through his paper.

Jeffrey D. Sachs: This paper by William Nordhaus is as provocative and informative as it is timely. The Iran-Iraq conflict and its portents for future oil prices and supply is another reminder of U.S. vulnerability in world energy markets. Nordhaus argues that a policy response to OPEC can be availing, that OPEC prices can in part be brought within U.S. control. The paper not only serves up the Nordhaus policy mix, but it details his recipe as well. In the end I find the preparation not only edible, but a delicacy; the policy conclusions are novel and sound. But as with many a stew, I can do without some of Nordhaus' ingredients. I offer in these comments a slightly altered recipe, with a little less fat and a bit more spice.

Most economists argue that the response to high world energy prices should be deregulation (perhaps with redistribution) and no more. Nordhaus goes further by pointing out that shifts in OECD demand rebound strongly on OPEC prices, so that policy-induced shifts in demand may well alter the real costs of imported oil. Nordhaus' argument can be stated in terms of an optimal tariff. The marginal importer of oil raises the import price of both marginal and inframarginal units. The marginal social cost is thus not the price of imported energy, $P_{E}$, but rather $P_{E}\left(1+1 / \epsilon_{S}\right)$, where $\epsilon_{S}$ is the OPEC supply elasticity (which I discuss below). Welfare maximization by importers (without OPEC retaliation) argues for a corrective joint tariff of $1 / \epsilon_{s}$. A subset of importers with a share $\theta$ of the imports would impose a smaller tariff in the amount $\theta /\left(\epsilon_{S}+(1-\theta) \epsilon_{D}^{\prime}\right)$, where $\epsilon_{D}^{\prime}$ is demand elasticity for oil imports by the rest of the world. All this is well known-and too often forgotten. A second argument for a tariff on oil may rest on national security grounds. Although this possibility has received some attention by economists, Nordhaus does not discuss the point. ${ }^{1}$

1. See George S. Tolley, and John D. Wilman, "The Foreign Dependence Question," Journal of Political Economy, vol. 85 (February-June 1977), pp. 323-93. 
In a static framework, it is easy to show that the welfare gains from a given ad valorem tax are largest for (1) inelastic OPEC supply, (2) elastic domestic energy supply, (3) highly elastic derived demand for oil, and (4) common tariff action by all importers rather than unilateral U.S. action. To gauge the accuracy of Nordhaus' intertemporal model, one must turn to his judgment on these four conditions. The assumptions must be carefully scrutinized because Nordhaus performs no sensitivity analyses for his model. On most scores, except for condition 4, I am even more optimistic than Nordhaus on the benefits of a tariff.

Nordhaus leaves the distinct impression that his policy conclusions follow from an unconventional view of OPEC. I strongly urge that this is not the case; the main competing view of OPEC can deliver the same policy recommendations. For Nordhaus, OPEC is a multiheaded entity, capable of coordination only to stop price cuts but never to engineer price increases. Output is perfectly inelastic above a price floor, and perfectly elastic below. Because $\epsilon_{S}$ is small above the kink, the optimal tariff is large (condition 1), and can drive prices down to the kink in OPEC supply. Unaccountably, Nordhaus chooses a nominal rather than a real price floor for his simulations of future policies, although OPEC has recently made explicit plans to include contract indexation.

The competing view of OPEC is of a collusive (one-part, two-part, or Nash-Cournot) cartel that is intent on intertemporal wealth maximization. ${ }^{2}$ I find little in Nordhaus' paper to convince me that his view is preferable to the latter. A cartel model better predicts the large cuts in production relative to capacity that sent prices spiraling in 1973-74. The Pindyck optimizing model of OPEC predicts well for the 1973-78 period. The decline in real oil prices during 1974-78 does not condemn the op-

2. Leading articles in this area include several by Robert S. Pyndick: "Some Long-Term Problems in OPEC Oil Pricing," The Journal of Energy and Development, vol. 4 (Spring 1979), pp. 259-72; "OPEC's Threat to the West," Foreign Policy, no. 30 (Spring 1978), pp. 36-52; "Pricing Policies of a Two-Part Exhaustible Resource Cartel: The Case of OPEC," European Economic Review, vol. 8 (August 1976), pp. 139-54; and "Gains to Producers from Cartelization of Exhaustible Resources," Review of Economics and Statistics, vol. 60 (May 1978), pp. 238-51. Stephen W. Salant has also made several key contributions including "Exhaustible Resources and Industrial Structure: A Nash-Cournot Approach to the World Oil Market," Journal of Political Economy, vol. 84 (October 1976), pp. 1079-93; and Imperfect Competition in the International Energy Market: A Computerized NashCournot Model, prepared for the Office of Policy and Evaluation, Department of Energy (Washington, D.C.: ICF Incorporated, May 1979). 
timizing model; it is predicted by it! Nor does the 1979 episode allow us to choose: Pindyck's model seriously underpredicts the post-Iran oil price increase, but so does the Nordhaus model. In recent weeks there has been further evidence against a literal fixed-output case. Saudi Arabia, Kuwait, the United Arab Republic, and Venezuela have announced that they will cancel planned cutbacks in view of the Iran-Iraq war. Mexico similarly has announced an acceleration of development plans for 1981 .

Even if OPEC is an intertemporal optimizer, there is still scope for a tariff. The OPEC supply response to a tax may still be zero if the tax is executed well. To take an extreme illustration, an ad valorem tariff on OPEC will be wholly borne by OPEC if extraction costs are zero, and if OPEC optimizes taking the tariff as given. ${ }^{3}$ Indeed, with extraction costs, such a tax could reduce tariff-inclusive prices upon imposition, though prices will eventually exceed the no-tariff prices.

Nordhaus is too quick on condition 2 above. He treats non-OPEC oil supply as exogenous and fixed and totally ignores non-OPEC, nonoil energy resources. Large oil finds are continuing. Some recent estimates put Mexican oil production in the range produced by Saudi Arabia by the late 1980s. ${ }^{4}$ More importantly, nonoil energy sources can be substantially expanded throughout OECD and the non-OPEC developing world. Nordhaus himself argues that nonpetroleum sources are not resource constrained. Besides the transport sectors there is a significant possibility of interfuel substitution toward these other energy supplies. ${ }^{5}$ Because the non-OPEC supply elasticity is higher than supposed, the tariff case is strengthened.

Similarly, I urge higher long-run demand elasticity estimates. Nordhaus uses an overall energy-demand elasticity for his oil-elasticity parameter and ignores the possibility of interfuel substitutability. More importantly, I rely more heavily than Nordhaus on elasticity estimates across countries. These are more likely than single-country measures to reflect

3. This assumes no strategic gaming by OPEC, that is, a pure Stackelburg solution vis-à-vis OPEC. For a good discussion of tax incidence in exhaustible resource markets, see Joseph Stiglitz, Partha Dasgupta, and Geoffrey Heal, "The Taxation of Exhaustible Resources," Discussion Paper 436 (National Bureau of Economic Research, January 1980).

4. An estimate of $8 \mathrm{mmbd}$ is cited in Pindyck in "Some Long-Term Pricing Problems in Oil Pricing," p. 261.

5. Some measurements of interfuel substitutability for a variety of sectors and countries may be found in Robert Pindyck, The Structure of World Energy Demand (MIT Press, 1979). 
long-run adjustment to energy price changes. Recent OECD data are revealing: the energy intensity of gross domestic product in Canada and the United States, countries that historically have low energy prices, is almost double the rates in Japan and Europe. ${ }^{6}$

Finally, I am disturbed by the cavalier treatment by Nordhaus of capital and its implication for his energy demand estimates. He states in every section that energy demand is embodied in capital, that "energy use is closely tied to the capital stock, and patterns of consumption and productivity change mainly as the capital stock changes." Yet the curtain comes down on Nordhaus' Hamlet without an appearance of the Prince! There is no capital in the model, only energy and labor. The intertemporal shifts in energy demand that Nordhaus models are surely skewed by the absence of investment fluctuations. More important, a prime long-run effect of an oil price increase is a reduction in capital intensity in the economy, as savings adjust to a reduced before-tax rate of return in investment. ${ }^{7}$ The decline in capital accumulation, evident throughout the OECD after 1973, has crucial implications for long-run output levels and energy demand, which is effectively made more elastic.

Part of Nordhaus' enthusiasm for an import tariff follows from his maintained assumption that the energy tax is jointly imposed within the OECD or the International Energy Agency. The Nordhaus model is not equipped to analyze the effects of an oil tax confined to the U.S. economy, but that may be the realistic policy choice. The effects of a U.S. tax on OPEC prices would surely be far lower than the Nordhaus estimates (the United States now represents only 30 percent of the world oil market), and the costs of a tax by only the United States would be higher. In the short run, higher domestic prices of oil would impose a burden on U.S. capital relative to capital in other economies. Other estimates of a sole U.S. policy move have not been sanguine. ${ }^{8}$

The assessment of whether the OECD will impose a joint policy is

6. In 1978 the total primary energy requirements (metric oil equivalents) divided by gross domestic product at constant 1975 U.S. prices were 1.05 , United States; 0.60, Japan; 0.58, Germany; 0.50, France; 0.85, United Kingdom; and 1.14, Canada.

7. For a quantitative assessment of long-run effects, see Jeffrey D. Sachs, "Energy and Growth Under Flexible Exchange Rates: A Simulation Study," in J. Bhandari and B. Putnam, eds., The International Transmission of Economic Disturbances Under Flexible Exchange Rates (forthcoming).

8. See, for example, Salant, "Imperfect Competition in the International Energy Market." 
probably best left to political scientists. But the 1973-79 record is far from promising for U.S. action, much less a common front. Rather than taxing imports, the United States has continued to subsidize imports ( $\$ 3.07$ a barrel in 1979), while real tax levies on gasoline have declined throughout the industrial world. ${ }^{9}$

Nordhaus eschews much discussion about the short run, and focuses instead on the time horizon in which "economic dials" can be set at desired levels. This analytical division of labor makes a lot of sense. But of course, Nordhaus cannot resist a few comments on short-run adjustment. Neither can I. Briefly, I take issue with his estimate that "of the 1.8 percentage points slowdown [in real growth], only 0.11 point is attributed to the oil crisis," and only 0.13 percentage point of the productivity slowdown. First, the growth of potential output in his model cannot rapidly slow down because there is no reproducible capital; energy is used in fixed proportion in the short run; and there is no scrapping of old vintages. The result is built in, not derived. Moreover, the gap between actual and potential gross domestic product is governed wholly by a single policy-reaction function. There is no aggregate demand calculation, and no possibility of a sudden decline in demand unaccommodated (or magnified!) by macroeconomic authorities. Nor does Nordhaus introduce current account targets into the authority's reaction function, though external balance was clearly a matter of great concern to policymakers.

More important, in my view, is the absence of any short-run linkage from profitability to output and investment. In a recent study in Brookings Papers I argued that the prolonged stagnation in European economies has resulted from a profit squeeze that was intensified by the oil shock of $1973-74 .{ }^{10} \mathrm{I}$ believe that recent experience with the 1979 oil price increase adds strength to this view. In Europe and Japan real wages have substantially moderated in response to the shock, and investment and employment have remained far stronger than in 1973-74. Recent OECD Economic Surveys for Germany and Japan cite the great modera-

9. The value of entitlement claims is published in the Monthly Energy Review of the U.S. Department of Energy. A good account of gasoline taxation in the West since 1970 is found $\rightarrow$ Alan A. Tait and David R. Morgan, "Gasoline Taxation in Selected OECD Countries, 1970-79," International Monetary Fund, IMF Staff Papers, vol. 27 (June 1980), pp. 349-79.

10. Jeffrey D. Sachs, "Wages, Profits, and Macroeconomic Adjustment: A Comparative Study," BPEA, 1979:2, pp. 269-319. 
tion in recent wage developments as a prime factor in the reduced impact of this oil shock over the last.

Nordhaus' stimulating analysis could not have come at a more propitious time. Although I disagree with parts of his approach, the overall call to a sensible tax-based middle-run energy policy is appropriate and important. We should thank Nordhaus for his efforts and hope that the paper plays a significant role in the future policy debate.

\section{General Discussion}

Peter Kenen and Charles Holt supported Nordhaus' modeling of OPEC pricing behavior. Holt reasoned that members of OPEC were sensitive to military pressures and to a variety of other noneconomic influences. They needed acceptable reasons for their pricing actions and the model of responding to spot prices made sense in that context. Kenen suggested extending the model so as to make long-run oil supply endogenous by explaining oil exploration and development in an optimizing framework. He also suggested modeling the accumulation of oil inventories so that total demand in a year such as 1979 could be better explained and anticipated.

Several panel members questioned Nordhaus' method of accounting for the effect of higher oil prices on productivity. Christopher Sims felt that it might be unduly restrictive to estimate the effect from the potential output equation, which used a fixed distributed lag on the price of oil relative to wages to estimate the substitution of labor for oil in producing GNP. He suggested that one could instead assume that changes in relative prices caused all the productivity slowdown and observe what this implied for the other parameters, including the dynamics of the adjustment process. Sims mentioned that the failure of macroeconomic management associated with the oil shock might have contributed to the productivity decline in ways that were not captured by normal cyclical adjustment. Jeffrey Sachs and Robert Gordon added that oil prices may have affected productivity by reducing investment, either directly because they made some investments uneconomic or indirectly because they reduced actual output and utilization. William Brainard suggested elaborating Nordhaus' vintage model to make retirements from the capital stock endogenous in order to analyze the effects of oil prices on productivity more fully. 
Nordhaus defended the magnitude of the productivity effects that he attributed to higher oil prices. Because oil prices accounted for only about $1 \frac{1}{2}$ percent of OECD GNP, it is hard to understand how substitution away from oil could have generated a massive decline in productivity. $\mathrm{He}$ disagreed with Sims' suggestion for assigning all the productivity slowdown to energy prices, maintaining that one had to specify clearly the transmission mechanism through which productivity was affected. He also pointed out that the weakness in investment could have come from many sources and that it could not, in any case, account for much of the productivity slowdown according to conventional estimates of the effect of investment on productivity. Nordhaus noted that his analysis may have missed some inefficient and irrational responses to higher oil prices such as the lowering of speed limits that reduced truckers' productivity, but he despaired of quantifying such effects and doubted that they should be modeled as predictable responses for the future.

Several discussants questioned Nordhaus' treatment of inflation and doubted whether the inflation of the 1970s could be explained without assigning a major role to higher oil prices. Robert Lawrence noted that an analysis by the OPEC secretariat found larger effects on inflation from oil prices. Sachs pointed out that the wage response in the United States was very different from the response elsewhere in OECD. In Europe and Japan nominal wages quickly responded to the first OPEC price explosion, while they did not in the United States. He added that the reaction outside the United States to the 1979 oil price increases has been very different and less inflationary than in 1973-74, indicating that labor in Europe has learned that a real wage decline was inevitable. James Tobin argued that the general form of the equation for wage inflation might be appropriate for most periods, but not when a large price shock has reduced real wages. The short-fall of the real wage level below expectations might speed up money-wage inflation temporarily, but real wage expectations will gradually adjust to experience. He suggested that OPEC and other one-time price shocks should be introduced into wage equations so that their effects on money-wage inflation decayed gradually over time. In support of his estimates of the effect of oil prices on inflation, Nordhaus noted the small share of oil value in GNP and the fact that inflation rates were already high before the OPEC shock. In 1973, OECD wage rates were rising at about 12 percent a year before the oil shock, and productivity growth had slowed to about $2 \frac{1}{2}$ percent a year. This implies 
an underlying inflation rate of close to 10 percent. In addition, prices of food and other commodities besides oil rose sharply in 1973, helping explain the added inflation of that period.

Several more general comments were made on the macroeconomic model. Alan Blinder argued that the major economies should be estimated separately rather than as an OECD aggregate. Blinder observed that the European economies had different structures, different policy responses, and different energy endowments from those of the United States. Lawrence commented that the regression coefficients estimated for OECD aggregates often resemble those of the United States because it accounts for much of the variance in OECD time series, with movements in other countries offsetting one another in the aggregate. Gordon believed the inflation equations were misspecified because they failed to model the rate of change in the output ratio. He also suggested that the use of output in a price equation might introduce a spurious negative relation between prices and output, first because of measurement errors-real output is derived by deflating nominal output by prices so that an overstatement of prices leads to an understatement of output-and second because economic policy might introduce a negative correlation if attempts were made to keep nominal income constant in the face of supply shocks that raised prices. He also reasoned that Nordhaus should have allowed for an increasing natural rate of unemployment as many other models of European economies did in explaining the 1970s.

The discussion also dealt with optimal policies in the oil market. Several participants supported Nordhaus' recommendation to use higher prices on domestic oil use in order to restrict demand and thus head off higher world oil prices by OPEC. Robert Hall reasoned that, if one accepts the view that OPEC's price follows the spot market, the best policy would combine an oil inventory to offset sudden shifts in excess demand together with an oil tax that is used only as needed. In response to emerging excess demand, initially the stockpile could be used to keep the world market price low while taxes were raised to restrict demand by users and thus bring oil back into the reserve. Holt argued for an optimal policy that subsidizes energy-efficient forms of investment. He urged the extension of Nordhaus' vintage capital model to explore the benefits of such an approach. 